ISSN: 0213-2079 - ISSN electrónico: 2386-3889

DOI: https://doi.org/10.14201/shhmo2017391229262

\title{
¿EL HÁBITO HACE AL MONJE? INSTITUCIONALIZACIÓN DE LA CARRERA JUDICIAL EN ESPAÑA A FINALES DEL ANTIGUO RÉGIMEN
}

\section{Do Clothes Make the Man? Institutionalisation of the Judi- cial Career in Spain at the End of the Old Regime}

\author{
Manuel Amador GONZÁLEZ FUERTES \\ Universidad Complutense de Madrid \\ Correo-e: manuelamadorgf@gmail.com
}

RESUMEN: La normativa de 1783, 1788 y 1799 inicia la institucionalización de la «carrera de varas» en la Monarquía Hispánica. El análisis de estas leyes permite observar los cambios y las limitaciones de la «segunda naturaleza» de los corregidores y alcaldes mayores durante la Ilustración. Sin modificar su caracterización moral, se intenta incrementar su capacitación técnica, su carácter letrado. Se analizará después la producción intelectual (libros, conferencias...) a la que la normativa dará lugar para acercarnos, finalmente, a la realidad práctica con ejemplos en donde se pueda comprobar el alcance real de estas medidas.

Palabras clave: Carrera judicial; habitus; Absolutismo; Corregidores; Alcaldes Mayores.

ABSTRACT: The regulations of 1783, 1788 and 1799 started the institutionalisation of the judicial career in the Spanish Monarchy. The analysis of these rules permit observing the changes and the limitations of the judicial officials and judges' ethics during the Enlightenment. The aim was to raise their technical ability, their legal nature, without modifying their moral characterisation. Afterwards, it will be analysed the intellectual production (books, conferences...) to which the regulations would give rise in order

(C) Ediciones Universidad de Salamanca / ®@ Stud. his., H. ${ }^{a}$ mod., 39, n. 1 (2017), pp. 229-262 
MANUEL AMADOR GONZÁLEZ FUERTES

¿EL HÁBITO HACE AL MONJE? INSTITUCIONALIZACIÓN DE LA CARRERA JUDICIAL EN ESPAÑA A FINALES DEL ANTIGUO RÉGIMEN

to approach reality by means of examples in which the full extent of these measures can be examined in the end.

Key words: Judicial Career; Habitus; Absolutism; Corregidores; Alcaldes Mayores.

«Dicen que el hábito es una segunda naturaleza. Quién sabe, empero, si la naturaleza no es primero un hábito» (Blaise Pascal) ${ }^{1}$.

\section{INTRODUCCIÓN: ENTRE LA ASIMILACIÓN Y LA SIMULACIÓN}

Blaise Pascal defenderá en esta famosa cita que, en el fondo, somos lo que aprendemos, lo que asimilamos. Poco antes, anticipará la misma idea en otro pasaje:

Que son nuestros principios naturales, sino nuestros principios acostumbrados? En los niños, los que han recibido de las costumbres de sus padres, como en los animales el cazar. Una costumbre diferente inspirará otros principios naturales. Esto se vé por experiencia. Y ya que haya algunos que no puede borrar la costumbre, tambien hay otros que no puede borrar la naturaleza. Esto depende de la disposición ${ }^{2}$.

La referencia a Pascal resultará fundamental para la obra de Pierre Bourdieu ${ }^{3}$, el verdadero redescubridor del concepto de la «segunda naturaleza», por otra parte una referencia clásica en la historia del pensamiento. Pero, además, Blaise Pascal, como demuestra la publicación que ha servido para llevar a cabo la traducción, era

1. La cita completa es: «Les pères craignent que l'amour naturel des enfants ne s'efface. Quelle est donc cette nature sujette à être effacée? La coutume est une seconde nature, qui détruit la première. Pourquoi la coutume n'est-elle pas naturelle? J'ai bien peur que cette nature, ne soit elle-même qu'une première coutume, comme la coutume est une seconde nature» (PASCAL, B.: Pensées de M. Pascal sur la religion, et sur quelques autres sujets, qui ont esté trouvées après sa mort parmy ses papiers. París, 1669, p. 199). Siendo traducida por Basilio Boggiero -utilizando el nombre de su hermano Andrés (RAmón Solans, F. J.: «La Virgen del Pilar dice...» Usos políticos $y$ nacionales de un culto mariano en la España contemporánea. Zaragoza, 2014, p. 77)-: «Los padres temen no se borre el amor natural de los niños. ¿Pues qué naturaleza es esta, expuesta a ser borrada? La costumbre es una segunda naturaleza que destruye la primera. En que consiste que la costumbre no es natural? Harto temo que esta naturaleza no sea una costumbre primera, asi como la costumbre es una segunda naturaleza» (PAscal, B.: Pensamientos de Pascál sobre la religión traducidos al español por don Andrés Boggiero. Zaragoza, 1790, p. 172).

2. PASCAL, op. cit., pp. 171-172.

3. Bourdieu, P.: Meditaciones pascalianas. Barcelona, 1999 (1. a edición en París, 1997).

(C) Ediciones Universidad de Salamanca / ®@ Stud. his., H. ${ }^{a}$ mod., 39, n. 1 (2017), pp. 229-262 
un pensador bien visto en la Europa ilustrada y, más en concreto, en la monarquía hispana del siglo XviII.

Porque la idea de la posible educación del comportamiento humano fue una de las principales que desarrollaron los pensadores, y con ellos los gobernantes, a lo largo de la centuria ilustrada. Más allá de la posible inquietud religiosa que pudiera ocasionar la variable de la cita por la cual los comportamientos adquiridos podrían ocupar la totalidad de la esencia humana, lo significativo para la mentalidad del absolutismo radicaba en la posibilidad de influir en el cuerpo social que la aprehensión de diferentes comportamientos, realizada a través de la educación, podía provocar. Tal idea no era nueva, pues la relación entre lo innato y lo adquirido era uno de los vectores básicos de la filosofía clásica, siendo aceptada con naturalidad, pues como magistralmente Kantorowicz puso de manifiesto, el propio monarca tenía una dualidad entre su cuerpo humano y la dignidad monárquica sacralizada ${ }^{4}$.

La referencia al trabajo de Kantorowicz tendrá su trascendencia en este mismo texto porque las pretensiones de los gobernantes respecto a sus servidores, siguiendo la trasmutación holística del soberano, también tendrían un carácter completo. En términos de Bourdieu, pretenderán crear un «habitus» de comportamiento integrado e interiorizado para formar servidores en donde surja una «segunda naturaleza» que trasmute, por lo menos en su labor pública, su primitiva naturaleza en otra, la de servidor del monarca. La coartada regia serviría de base para efectuar este intento entre sus servidores.

Ya en las Partidas se dejaba claro que la justicia era una de las primeras regalías de los monarcas ${ }^{5}$ pero, ante su incapacidad de llevarla a cabo, se vio en la obligación de delegar esta función aunque, no solamente en teoría, cualquier apartado judicial podía ser sancionado y decidido por el monarca y existen ámbitos, como el de la justicia distributiva de la gracia regia, que seguirán siempre cercanos a la figura del monarca. Pero en la delegación del poder de juzgar iba implícito, desde un principio, la necesidad por parte del delegado real, el magistrado, de comportarse de una determinada manera que mantuviese la dignidad regia a salvo. Un juez, por lo menos en teoría y de cara al exterior, tenía que cumplir una serie de requisitos, establecidos más en el marco moral y de comportamiento que en la plano de los conocimientos legales, consustanciales a su figura, que se establecieron a partir del momento de la delegación de la justicia por el monarca y que debía cumplir desde su incorporación a las tareas

4. Kantorowicz, E. H.: Los dos cuerpos del rey. Un estudio de teología política medieval. Madrid, 1985 (1. ${ }^{\text {a }}$ edición: Princeton, 1957).

5. Partida 2, título I, Ley I.

(C) Ediciones Universidad de Salamanca / ®@ Stud. his., H. ${ }^{a}$ mod., 39, n. 1 (2017), pp. 229-262 
de juzgar. Esta «segunda naturaleza» traspasaba el simple cumplimiento de un tipo de comportamiento más o menos normativizado trascendiendo el nivel de conocimientos o su propia naturaleza. Se convertía así en un «habitus» que fijaba y reglaba su comportamiento y, en el mejor de los casos, se interiorizaba, en la mejor línea de Bourdieu, armonizando lo subjetivo -tanto consciente como inconsciente- del individuo con lo objetivo propuesto por la sociedad en cuanto a cómo debía comportarse un magistrado.

La creación de esta «segunda naturaleza» se inició históricamente en el momento de la delegación del poder de juzgar y tenía implicaciones en cualquier faceta del comportamiento del juez, incluidas algunas que en el mundo actual se circunscriben a las más privadas de la personalidad, como era el caso del elevado número de solteros en la carrera judicial, llegando incluso a poner en duda la capacidad del juzgador por sus características físicas como se comprueba en casos como la sordera, ceguera o baja estatura.

Nuestro análisis se concentrará en una pequeña parte de las personas que podían juzgar en la Monarquía Hispánica durante un período de tiempo relativamente pequeño pero que consideramos fue altamente significativo en la evolución de lo que actualmente entendemos como juez ${ }^{6}$. Nos fijaremos en los corregidores y alcaldes mayores de territorios realengos con jurisdicción ordinaria en tierras peninsulares durante los últimos años del siglo XVIII -desde las reformas de 1783hasta la implantación de los juzgados liberales de primera instancia en 1834. En pocas palabras, se podría hablar del momento de la instauración de la «carrera de varas» -en contraposición a la «carrera togada» que desarrollaban los magistrados de los tribunales territoriales y de los consejos- a finales del Antiguo Régimen. Y será precisamente este intento de formación de una «Carrera» la que creemos que ocasionará cambios en esta «segunda naturaleza» entre un grupo de servidores regios que se autodefinirán y serán definidos como un «cuerpo» individualizado y como tal interactuarán para, siguiendo los cánones del Antiguo Régimen, conseguir una situación privilegiada a cambio, eso sí, de manifestarse con esta idiosincrasia propia que asimilarán o simularán.

Pero, antes de continuar, deberemos llamar la atención sobre una serie de consideraciones previas que aclaren nuestros objetivos y delimiten nuestros propósitos. En primer lugar, se advierte que nuestra intención no es realizar una historia de la institucionalización de la «carrera de varas» durante este período que aún está parcialmente por hacer a pesar de los estudios dedicados a este

6. Para el estatuto del juez: Roldán Verdejo, R.: Los jueces de la Monarquía Absoluta. Su estatuto y actividad judicial. Corona de Castilla, siglos XIV-XVIII. Santa Cruz de Tenerife, 1989.

(C) Ediciones Universidad de Salamanca / ®@ Stud. his., H. ${ }^{a}$ mod., 39, n. 1 (2017), pp. 229-262 
punto por Gay Escoda ${ }^{7}$ y, con carácter más general, por González Alonso ${ }^{8}$ y Albi $^{9}$. Nos limitaremos a recoger los puntos que dentro de esta configuración general consideramos más trascendentes para la configuración de un modo de ser diferenciado, un «habitus».

En segundo lugar, conviene aclarar el tratamiento conjunto que damos tanto a los corregidores como a los alcaldes mayores, pues la mayoría de los estudios los diferencian y jerarquizan claramente. Aunque es verdad que muchos alcaldes mayores (en ocasiones llamándoseles tenientes de corregidor) dependían de corregidores no letrados (gobernadores o corregidores de capa y espada) y de corregidores letrados (en Sevilla del Asistente) en ciudades muy populosas, los reformadores ilustrados pretendían modificar el «habitus» específicamente del mundo letrado de la «jurisdicción ordinaria», paso previo a la reforma de las «jurisdicciones privilegiadas» señoriales y de los territorios bajo control de las Órdenes Militares. Este proceso de regulación y control regio del mundo letrado se iniciará en 1749 cuando el monarca se atribuirá el nombramiento de los alcaldes mayores, hasta ese momento designados por los corregidores en una clara jerarquización ahora rota. La designación real va a provocar la paulatina ruptura de esta relación vertical al crearse alcaldías mayores que no dependían del correspondiente corregidor, fenómeno que se acentuará a partir de 1814 cuando Fernando VII se arrogue la designación de los cargos judiciales hasta ese momento enajenados en manos señoriales.

Por último, hemos suprimido conscientemente las referencias a la fidelidad política, elemento clave desde la invasión francesa de 1808, la ruptura del monopolio a nivel práctico del absolutismo y la aparición de opiniones divergentes sobre la organización del sistema político. Dejando constancia de antemano que tales distensiones políticas son un elemento fundamental para comprender la evolución de la judicatura y de que están de por sí imbricadas en la definición de la naturaleza del juez, pues la fidelidad al sistema político es uno de los elementos claves en cualquiera de los sistemas ideológicos enfrentados, nuestra decisión deriva precisamente de que realmente el concepto en sí de fidelidad, entendida como lealtad, es el mismo aunque se aplique a ideales de organización social antagónicos.

7. Gay Escoda, J. M.: «La culminación de las reformas de la administración municipal durante la Ilustración: el establecimiento de la carrera de corregimientos y varas y la "Instrucción de corregidores”», Documentación jurídica, 60, 1988, pp. 1637-1759.

8. González Alonso, B.: El corregidor castellano (1348-1808). Madrid, 1970, pp. 243-285.

9. Albi, F.: El corregidor en el municipio español bajo la Monarquía absoluta (ensayo bistórico-crítico). Madrid, 1943, pp. 65-83.

(C) Ediciones Universidad de Salamanca / ®@ Stud. his., H. ${ }^{a}$ mod., 39, n. 1 (2017), pp. 229-262 
MANUEL AMADOR GONZÁLEZ FUERTES

¿EL HÁBITO HACE AL MONJE? INSTITUCIONALIZACIÓN DE LA CARRERA JUDICIAL EN ESPAÑA A FINALES DEL ANTIGUO RÉGIMEN

\section{LAS DISPOSICIONES NORMATIVAS: LA INDIVIDUALIZACIÓN DE LA «CARRERA DE VARAS» Y LAS ESPECIFICIDADES LETRADAS}

Como pone de manifiesto Gay, incluso en el título de su trabajo, en su pormenorizado análisis sobre las normas aprobadas en 1783 -una Real Cédula ${ }^{10}$ y un Real Decreto ${ }^{11}$, ambos de 29 de marzo de 1783- la trascendencia de esta nueva legislación será la creación de una «carrera de varas» para los corregidores y alcaldes mayores que no desempeñasen tales cargos por designaciones de tipo militar ${ }^{12}$. En la Cédula las deficiencias observadas («la escasa dotacion de estos empléos, su falta de prontos y proporcionados ascensos, y la corta duración de los empleados en sus respectivos destinos») se pretenden subsanar, para conseguir jueces caracterizados por su «integridad, instruccion, zelo y desinteres», intentando que el Consejo de Castilla aumente la dotación de los cargos (artículo III) e incrementando su duración a seis años (artículo IV) pero, fundamentalmente, a través de la creación de «tres clases» jerarquizadas en importancia y sueldo -entrada, ascenso y término- por las que obligatoriamente ascenderán los servidores del monarca.

Los efectos corporativos de esta Cédula fueron, más allá de la intención del monarca, mucho mayores que la propia creación de la «carrera de varas» que en ella se aprueba. La norma individualiza a los corregidores letrados y pone las bases, aunque la evolución posterior ayudará en otros aspectos, para formar un cuerpo letrado, separado del militar y del de los caballeros de capa y espada, al servicio de la Monarquía.

Así, en primer lugar, solo aparece una mención secundaria a los corregimientos gestionados por los gobernadores militares separándose nítidamente también a los servidores letrados (corregidores letrados y alcaldes mayores) de los que carecían de preparación jurídica (corregidores de capa y espada o políticos) aunque la intención del legislador pudiera no ser esa ${ }^{13}$, lo cual, si bien no era nuevo, se acentuará con el paso del tiempo hasta la supresión definitiva de los corregimiento políticos en

10. Real Cédula de S. M. y señores del Consejo, por la qual se establecen reglas y providencias que deben observarse en lo succesivo para el modo de proveerse y servirse los Corregimientos y Alcaldias mayores de los Reynos de Castilla y Aragon, é Islas adyacentes. Madrid, 1783.

11. Gazeta de Madrid.33, 25.4.1783, pp. 370-374.

12. Las alcaldías mayores eran desempeñadas por letrados, mientras que entre los corregimientos se establecían tres grupos (gobernadores militares con título de corregidor, corregidores de capa y espada y corregidores letrados) con dos vías de acceso (nombramiento por la Secretaría del Despacho de Guerra en el primer caso y a través de consulta de la Cámara de Castilla en los otros).

13. En el artículo VIII se abría una posible vinculación entre ambas carreras pero solo en el caso de que «faltare número competente de los sujetos que actualmente sirven». Esta posibilidad, en la práctica, nunca se llevó a cabo, pues siempre hubo suficientes pretendientes.

(C) Ediciones Universidad de Salamanca / ®@ Stud. his., H. ${ }^{a}$ mod., 39, n. 1 (2017), pp. 229-262 
1833 que no tuvo continuidad por las reformas del año siguiente ${ }^{14}$. Corregidores políticos y letrados formarán a la larga dos cuerpos bien diferenciados.

Además, se establecerán dos medidas que fomentarán el espíritu de cuerpo y aunque se apunte otra que iría en su contra, su fracaso posterior redundaría en la autorrepresentación individualizada de los jueces letrados. Por un lado, se vehiculará el acceso a la carrera exclusivamente a través de la incorporación a corregimientos de entrada fomentándose así los ascensos (artículo II) y se plantará el germen de la asistencia social a los jueces impedidos y la jubilación (artículo XI) mientras que, aunque se intente proporcionar un ascenso a la «carrera togada» a los corregidores y alcaldes mayores de «término» con diez y ocho años de servicio (artículo VII), la experiencia posterior -en donde en la mayoría de estos casos se concedieron más los honores, la antigüedad o incluso el sueldo de toga en audiencias y chancillerías que su propiedad efectiva- demostró que la salida del «cuerpo» era difícil lo que, a la postre, reforzaba su propio espíritu.

Un último punto recogido en el artículo VI conviene destacar en el análisis:

Que pasado el sexénio, ó en el caso de promocion no estén obligados los Corregidores, y Alcaldes mayores á dexar las Varas, miéntras no llegare el succesor, y entónces le habrán de entregar una relacion jurada y firmada, en que expresen con distincion las obras públicas de calzadas, puentes, caminos, empedrados, plantíos, ú otras que hubieren hecho, concluido ó comenzado en su tiempo, y el estado en que se hallaren, las demas que fueren necesarias o convenientes, segun su mayor necesidad ó utilidad, y los medios de promoverlas, el estado de agricultura, grangería, industria, artes, comercio y aplicación del vecindario, los estorvos ó causas del atraso, decadencia ó perjuicio que padezcan, y los recursos y remedios que pueda haber.

La realización de un pormenorizado informe sobre su labor, que se mantendrá en disposiciones posteriores ${ }^{15}$, tendrá consecuencias significativas, más allá del fondo documental que por este medio se podría haber generado, que a lo que parece no se llevó a cabo sistemáticamente, no se conservó o no se ha buscado. Estos informes resultan significativos por la percepción que proyectarían de sí mismos los propios corregidores y alcaldes mayores. Los jueces presentarían un informe de su gestión con un carácter general como máximos representantes judiciales y gubernativos de la Monarquía en las diferentes localidades lo que, por una parte, les obligaría a reflexionar sobre su labor y plasmar tales reflexiones

14. Archivo Histórico Nacional [en adelante AHN], Consejos [en adelante Cons,], leg. 13.285 y AHN, Cons., leg. 13.288.

15. Se repetirá en el artículo LXXIII de la Instrucción de 1788 y en el XIV de la Real Cédula de 7 de noviembre de 1799.

(C) Ediciones Universidad de Salamanca / ®@ Stud. his., H. ${ }^{a}$ mod., 39, n. 1 (2017), pp. 229-262 
en un documento oficial que podía servir para una valoración posterior de su actuación lo que, por otra parte, les llevaría a reflejar modelos ideales de gestión que plantean, a la vez, dudas sobre su autencidad, pero también proporcionan referentes de lo que estas autoridades consideraban como el modelo óptimo de su labor, una manifestación ideal en el ámbito práctico de su «segunda naturaleza» judicial. Un pálido reflejo de estos informes, manteniendo sucintamente -por su reducido tamaño- su carácter ideal, aparecerá en las relaciones de méritos de las que se hablará con posterioridad.

En cuanto al Decreto remitido a la Cámara lo más destacado para nosotros será, además de reforzar las medidas de la Cédula, los controles que fija para la incorporación a la carrera judicial en donde empieza a hacerse hincapié en «los estudios, grados y práctica forense que deben tener conforme á las leyes» aunque sin olvidar «sus costumbres, talentos y otras calidades necesarias para el gobierno de los pueblos».

Como recuerda Gay Escoda ${ }^{16}$ esta legislación fue bien recibida por los corregidores quienes, a su vez, elevaron tres representaciones en las que daban las gracias al monarca por la normativa y, en la última, firmada por Antonio Fernández Calderón y José Durán Flores hacían tres peticiones: que se adscribieran los corregidores y alcaldes mayores al Montepío del Ministerio y los Tribunales, que se les concediese un uniforme que les distinguiese de otras autoridades y que las residencias fueran realizadas por jueces de igual o superior categoría.

Destaquemos, en primer lugar, que la representación aparecía firmada por un corregidor letrado (Antonio Fernández Calderón, primer corregidor letrado de Cuenca) y dos alcaldes mayores (Lorenzo Mardones, de Orihuela y José Durán, de Granada) y sus reivindicaciones afectaban, como se comprueba en el caso de la utilización de la golilla, a los corregidores letrados. Pero también conviene reparar en dos de las peticiones: la de incorporarse al Montepío del Ministerio y los Tribunales y el deseo de abandonar el uso de la golilla. La primera estaba encaminada a salvaguardar la vejez y los posibles accidentes y enfermedades de estos servidores pero fue rechazada de pleno en la consulta posterior del Consejo de Castilla. Sin embargo, la resolución final del conflicto, con la creación del Montepío de Corregidores y Alcaldes Mayores -obsérvese que ambos tipos de jueces están unidos y que los letrados son en ellos la inmensa mayoría- por Real Decreto de 7 de noviembre de $1790^{17}$, ayudó tanto a separarlos de los magistrados y de la «carrera de toga» como a aumentar su espíritu de cuerpo. Respecto al uso

16. Gay Escoda, op. cit., pp. 1690-1694.

17. Nov. Recop. Lib. VII, tít. XI, ley XXXIII.

(C) Ediciones Universidad de Salamanca / ®@ Stud. his., H. ${ }^{a}$ mod., 39, n. 1 (2017), pp. 229-262 
de la golilla, puede que Gay tenga razón en afirmar que lo que subyacía en esta petición era abandonar el anticuado ropaje de juez pero también afirma que esta petición se vinculaba a la dificultad de ser distinguidos entre otras autoridades lo que resulta lógico siguiendo la mentalidad de la época, pues como «cuerpo» diferenciado deseaban tener ante el público una visibilidad individualizada.

De las disposiciones reales del 29 de marzo de 1783 surgieron dos expedientes. El primero, por el que se configuraró la escala de corregimientos, no tiene para nosotros tanto interés, pero sí el segundo que regulaba la forma de ingreso a la carrera $^{18}$, no solo por establecer los requisitos de entrada, sino porque en él se manifiesta de nuevo una nítida separación entre corregidores letrados y políticos ${ }^{19}$, además de equiparar, en cuanto a la vía de acceso, a los corregidores y alcaldes mayores de Ordenes con los letrados de la jurisdicción realenga ordinaria ${ }^{20}$.

Para estos servidores letrados se intentan primar los conocimientos en derecho. Así se unen obligaciones tradicionales (diez años de estudios de derecho, cuatro de ellos de práctica) con dos nuevas disposiciones: que en los exámenes de abogados se pregunte sobre «sobre las citadas leyes y capítulos de Corregidores, y sobre lo que establecen para el gobierno y policia de los pueblos», anunciándose una futura instrucción de corregidores que todavía tardará cuatro años, y, lo que resulta más novedoso, «que cada pretendiente letrado presente tambien algun trabajo, comentario ó disertacion sobre algunos puntos de las leyes y capitulos de Corregidores».

Al gestarse un grupo diferenciado caracterizado por su carácter letrado parece lógico que la Monarquía pretendiera exigirles la competencia práctica en lo que se estaba configurando como su naturaleza, tanto el de los conocimientos teóricos en derecho (de ahí la necesidad de los años de estudio) como en su plasmación a nivel práctico (los cuatro años de pasantía) pero también, lo más novedoso, en su

18. Gay Escoda, op. cit., pp. 1704-1715.

19. Tanto los corregidores letrados como políticos deben "presentar una informacion de documentos y testigos hecha con citacion del Sindico y Personero del lugar de su domicilio, en que conste donde ha residido los últimos 3 años; que es legitimo, y de edad de 26; y que es de buena vida y costumbres, y especialmente de conocida honestidad y desinteres», "que quando el domicilio de los pretendientes hubiere sido en la Corte ó en lugares de Audiencias y chancillerías se explique en la informacion el quartel ó barrio en que habiten» y «que las calidades unicas de preferencia en unos y otros sean las de su virtud y doctrina adaptable á sus oficios». A los pretendientes de corregimientos políticos se les exige «su talento y el de que hayan tenido algun encargo, comision ó motivo de imponerse en el conocimiento de los pueblos y su gobierno economico y politico» (Gazeta de Madrid, pp. 370-374).

20. Para los alcaldes mayores del territorio de Órdenes «se observe lo mismo que se ha servido prescribir para los Corregimientos de letras y Alcaldias mayores que consulta la Camara» permitiéndose la alternancia de destinos.

(C) Ediciones Universidad de Salamanca / ®@ Stud. his., H. ${ }^{a}$ mod., 39, n. 1 (2017), pp. 229-262 
correlato en el complejo mundo de los corregimientos y las alcaldías mayores. En este último aspecto se incide en los exámenes para la consecución del título de abogado, entre los cuales se deseaba reclutar al nuevo personal, y que como práctica ya institucionalizada resultaba más fácil de modificar. Nos acercamos a la instauración, nunca lograda, de una prueba objetiva de ingreso, que se refuerza con la obligación de presentar una «disertación» sobre temas legislativos y competenciales del mundo corregimental, verdadera novedad que aunque no se prolongue se presenta como un paso importante en la configuración de la carrera letrada, pues a través de la valoración de tal trabajo, que llevaron a la práctica las academias que surgieron en ese siglo, se pretendía hacer hincapié en la preparación práctica de los futuros jueces letrados. Se daba un paso más para intentar constituir una caracterización peculiar a este nuevo cuerpo en gestación, sus conocimientos letrados. En otras palabras, crear un «habitus» de comportamiento, una «segunda naturaleza».

En el proceso que venimos analizando la Instrucción de corregidores aprobada el 15 de mayo de $1788^{21}$ no supone un documento especialmente novedoso ni trascendente. En la sucesión de las competencias del corregidor y, por su último artículo, de los alcaldes mayores, solo destaca la reiteración, en el artículo LXXIII, de la obligación de la realización de un informe general al final del mandato ya comentado.

Tras diez años en funcionamiento, la Cámara de Castilla, todo indica que bajo iniciativa propia, elevará al monarca una consulta el 14 de marzo de 1798 para mejorar la situación de los corregidores y alcaldes mayores que iniciará un expediente ${ }^{22}$ que concluirá con una nueva Real Cédula, de 7 de noviembre de 1799, por la que se retocará la admisión y carrera de los jueces ordinarios.

Lo primero que llama la atención en este expediente será la constatación de la separación entre los juzgados letrados y los políticos. Aunque en su desarrollo se insertará una representación de 8 de octubre de 1794 de diferentes corregidores que se presentarán «a nombre de los demás sugetos que componen la clase de corregidores políticos», uno de los dos informes fiscales del expediente, el fimado por Domingo Codina el 30 de agosto de 1799, la desvinculará de la consulta que debe realizar la Cámara, criterio que seguirá la propia Cámara en su nueva consulta de 18 de septiembre de 1799. El hecho de que los autoproclamados corregidores políticos elevasen una representación propia, con un carácter claramente defensivo

21. Real Cédula de S. M. y señores del Consejo, en que se aprueba la instrucción inserta de lo que deberán observar los corregidores y alcaldes mayores del reyno. Madrid, 1788.

22. AHN, Cons., leg. 13.291.

(C) Ediciones Universidad de Salamanca / ®@ Stud. his., H. ${ }^{a}$ mod., 39, n. 1 (2017), pp. 229-262 
y objetivos individualizados ${ }^{23}$, denota ya la diferenciación dentro de la carrera corregimiental. La separación realizada por Codina y aceptada por la Cámara abunda en la misma idea. Además, la redacción final de la Real Cédula de 7 de noviembre ${ }^{24}$, aunque afecta a todos los corregidores y alcaldes mayores al no separar el elemento político del letrado, se realiza pensando exclusivamente en los jueces letrados pues a ellos son a los que afecta la mayor parte de las nuevas disposiciones.

La consulta de la Cámara (elevada por el gobernador José Ezpeleta, el marqués de Roda, José Mariño, José Antonio Fita y el marqués de Hinojosa y con el beneplácito, según referencia de la secretaría, del ausente José Eustaquio Moreno) fue acordada en la sesión del 26 de febrero de 1798 y elevada el 14 de marzo. Partía de la idea de que la reforma judicial de la década de los ochenta ocasionaba «graves inconvenientes y perjuicios» por la poca preparación de los pretendientes:

Son únicamente aquellos [abogados] que con el corto estudio que se requiere para obtener el grado de bachiller se retiran de la universidad, se agregan al bufete de un abogado para poder acreditar los quatro años de práctica que se requieren para entrar a recibirse en los tribunales y se ven sin principios o sin estudio competente para ganar de comer en la abogacía, atrasando y perjudicando si logran alguna vara o corregimiento de dichas dos clases últimas a los que ya están sirviendo en esta propia carrera ${ }^{25}$.

Así, las plazas no resultaban atractivas para los letrados ideales para la Cámara, que no eran otros que los buenos abogados. Nótese que entre los camaristas no se plantea la posibilidad de otros pretendientes con características más prácticas, como jueces de señorío, alcaldes entregadores de la Mesta o jueces de territorios de las Órdenes, lo que, por otra parte, corresponde a la realidad de los orígenes de los letrados ordinarios de la Monarquía. Las causas de este fracaso eran, según los camaristas, la inestabilidad en la carrera con periodos sin trabajo entre dos

23. Los corregidores políticos solicitan la reintegración de los corregimientos políticos que estaban en manos de gobernadores militares, que se adecúe el número de empleados al de empleos, que la media annata se arregle al sueldo efectivo y que solo se pague el aumento de salario en los ascensos, «que se prefije tiempo para conceder los honores de yntendente o del Consexo de Hacienda a los beneméritos y que [...] se asigne de las 18 yntendencias que hay de provincia, dos que precisamente sirvan de salida a esta clase con lo que se realizarán las piedades de vuestra Majestad» (AHN., Cons. Leg. 13.291). No se tiene información sobre que tal representación derivase en una legislación específica.

24. SÁnchez, S.: Colección de todas las pragmáticas, cédulas, provisiones, circulares, autos acordados, vandos y otras providencias publicadas en el actual reynado del señor don Carlos $I V$. Tomo III. Madrid, 1801, pp. 226-233.

25. AHN., Cons. Leg. 13.291.

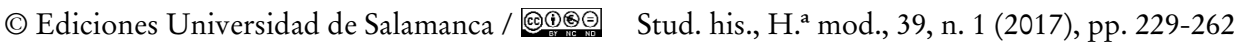


destinos, la movilidad judicial con los correspondientes gastos derivados de los traslados y la corta duración de los cargos que imposibilita el desarrollo de un trabajo eficaz y limitaba la autoridad del juez frente a los poderosos locales.

Ante tales problemas la Cámara presentará una serie de soluciones: limitar los parones en el servicio, consolidar la duración del empleo disminuyendo los traslados, ajustar el número de empleos a los posibles pretendientes, fijar los ascensos evitando los que no cumplan los requisitos legales, mejorar el pago de los salarios, encauzar los actos disciplinarios a través de los tribunales territoriales y el Consejo de Castilla, trasladar a los jueces hacia lugares cercanos y, por último, la medida más novedosa, crear una clase superior de varas, las de mayor salario y prestigio y que no enumera, para los jueces más antiguos y experimentados creando una nueva clase que aunque permanecerá en la consulta de la Cámara de 18 de septiembre de 1799 no será recogida en la Cédula posterior.

Que la iniciativa del expediente corrió a cuenta de la Cámara parece corroborarlo la misiva que el Secretario del Despacho de Gracia y Justicia, José Antonio Caballero, remitió en nombre del monarca a la Cámara el 28 de septiembre de $1798^{26}$, desusadamente larga y en la que introducía nuevos temas a tratar. Caballero mostraba reticencias sobre lo que consideraba la perpetuación de los empleos exigiendo una nueva opinión de la Cámara además de solicitar su dictamen sobre la pervivencia de los juicios de residencia y sobre «los requisitos para obtener la habilitación para corregimientos y varas de primera clase o entrada», en concreto sobre la disertación legal a presentar por el pretendiente, «sin olvidarse de que podrá ser mui conducente que se atienda con particularidad a la educación de los pretendientes, ya sea conocida o ya presumpta por la calidad de su nacimiento».

Con la intervención de Caballero el expediente tomará un nuevo rumbo centrado en los nuevos temas propuestos por el ministro y en las dudas planteadas por la, según Caballero, perpetuidad de los empleados de varas. Aunque será este tema de la perpetuidad el que marque las opiniones de los dos informes fiscales que se solicitarán y de la consulta posterior de la Cámara, defendiendo su punto de vista frente al general rechazo de los fiscales y el ministro, para nuestros fines resultan de más interés las dudas planteadas por Caballero en cuanto a la forma de acceso a la carrera y la «naturaleza» de los jueces.

La misiva de Caballero volverá el expediente a la Cámara que solicitará el informe de su fiscal por acuerdo de 3 de octubre de 1798. El 25 de enero de 1799 el ministro de Justicia reclamará de nuevo el pronunciamiento de la Cámara que volverá a insistir a Hermida el día 28. Con fecha de ese mismo día el fiscal

\section{Ibidem.}

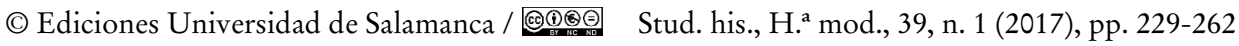


Hermida firmará un informe, criticado con posterioridad por los camaristas, que esperarán al nombramiento de un nuevo fiscal -al ser ascendido Hermida a camarista-, Domingo Codina, para solicitarle un nuevo informe, fechado el 30 de agosto de 1799, más del gusto de la mayor parte de los magistrados, quienes emitirán su consulta, en la que se incluye fiel estracto de ambos dictámenes, el 18 de septiembre de $1799^{27}$.

Los dictámenes de ambos fiscales y la consulta de la Cámara no diferirán en el fondo respecto a la cuestión sobre la «naturaleza» que debían de tener los jueces de la carrera de varas presentado de manera algo ambigua por Caballero («diga la Cámara si para entrar en la de la toga convendrá imponer además del número de años que previene la ley, ciertas pruebas de calidad, particulares estudios u otros medios que aumenten la confianza que deve tenerse de tan distinguidos ministros»). La línea de argumentación vino marcada por el informe de Hermida que vinculó la sugerencia de Caballero al posible carácter nobiliar de los corregidores y alcaldes mayores no rechazando, en principio, tal idea aduciendo la mejor educación que según su criterio tenía la nobleza y el aumento de status que el carácter nobiliar tendría en el oficio, pero el fiscal se guardará de proponer el carácter nobiliario de la carrera de varas:

No parece es necesario, para darle mayor realze, hacerla paso preciso [la nobleza] para entrar en los tribunales, de lo que podrían seguirse inconvenientes en perjuicio de los sugetos de distinguido mérito y talento que se forman en las universidades y adquieren particulares luzes en otras ocupaciones no menos importantes ${ }^{28}$.

La opinión de Codina no difiere de la de Hermida aunque, en este caso, cargará más las tintas sobre la indiferencia del carácter nobiliar del empleo con expresiones tales como «ni los vicios ni las virtudes se heredan de los padres» $\mathrm{O}$ «la nobleza de por sí y el lustre de la sangre no preservan a la posteridad del contagio de la corrupción» y sobre los perjuicios que ocasionaría tal disposición, recogido posteriormente por la Cámara en su consulta definitiva:

Con todo limitar a sola la clase de nobles la posesión de los empleos de magistratura o exigir por ley y precisión esta calidad se persuade el Fiscal sería hacer un agrabio a la mayor parte de vasallos honrados y hombres buenos que destituidos de bienes de fortuna no pueden acreditarla. Sería acaso abrir el fraude y abibar la cabilación y empeño de ingerirse en la clase que por desgracia harto común, no perdonan al rigor de las leyes reglamentarias más severas que la exigen, para la admisión de sugetos

27. Consultaron el marqués de Roda, José Mariño, José Antonio Fita, José Eustaquio Moreno, el marqués de Hinojosa y Sebastián Piñuela.

28. AHN., Cons. Leg. 13.291.

(C) Ediciones Universidad de Salamanca / @@@ Stud. his., H. ${ }^{\text {a }}$ mod., 39, n. 1 (2017), pp. 229-262 
MANUEL AMADOR GONZÁLEZ FUERTES

¿EL HÁBITO HACE AL MONJE? INSTITUCIONALIZACIÓN DE LA CARRERA JUDICIAL

EN ESPAÑA A FINALES DEL ANTIGUO RÉGIMEN

en las órdenes e incorporaciones más distinguidas. Sería sobre todo cerrar la puerta al mérito de muchos vasallos y con ello impedirles la proporción de ennoblecerse por la carrera de las letras que como otras eleban a los sugetos por grados a las más altas clases del Estado ${ }^{29}$.

Aunque finalmente en la Cédula de 7 de noviembre de 1799 no se hizo referencia a este tema parece indudable que la consideración o no de la nobleza como necesaria para entrar en la carrera de varas afectaría a la naturaleza del juez. Más allá de la consideración de tal medida como regresiva, que no deja de ser un juicio de valor sin mucho significado, conviene llamar la atención -además del hecho de que las reflexiones derivaron de la interpretación dada por Hermida a las ambiguas palabras de Caballero- de una aparente paradoja, pues la reflexión sobre el carácter noble de estos jueces resultaba congruente en el marco general de la naturaleza exigida a tales servidores y, a la vez, incongruente con la formación de una carrera letrada de varas.

Los ideales exigidos de manera tradicional a los corregidores y alcaldes mayores eran complementarios a los requeridos a la nobleza. De ahí, por otra parte, la presencia de corregidores de capa y espada a los que no se exigía una formación letrada. En tanto que estos valores exigibles se perfilan pero no eliminan con las reformas ilustradas, que este tema diera lugar a una posible reflexión no resulta ni sorprendente ni incoherente. Sin embargo, incluir en el contexto de estas reformas el carácter nobiliario de los jueces resultaba incongruente en tanto se intentaba formar un cuerpo en el que la capacitación técnica letrada no solo constituyese una parte de su naturaleza sino la esencia diferenciadora de la misma. En otras palabras, no se pretendían establecer corregidores políticos letrados sino simplemente corregidores letrados.

La crítica del monarca, vehiculada a través de Caballero, sobre algunos requisitos necesarios para incorporarse a la carrera de varas era mucho más explícita en la carta del ministro de 28 de septiembre de 1798 poniendo claramente en duda la utilidad de las disertaciones en el proceso de selección. Esta claridad del monarca debe ser tenida en cuenta para valorar las opiniones vertidas por los fiscales y por la Cámara. No podemos concluir que los autores de tales textos mintiesen sobre este punto, pero sí conviene reparar en la influencia de la opinión real en la configuración de los dictámenes. Todos coinciden en un primer aserto que resume escuetamente la consulta de la Cámara:

\section{Ibidem.}

(C) Ediciones Universidad de Salamanca / ®@ Stud. his., H. ${ }^{a}$ mod., 39, n. 1 (2017), pp. 229-262 
MANUEL AMADOR GONZÁLEZ FUERTES

¿EL HÁBITO HACE AL MONJE? INSTITUCIONALIZACIÓN DE LA CARRERA JUDICIAL EN ESPAÑA A FINALES DEL ANTIGUO RÉGIMEN

Que mientras no se arregle el estudio de la jurisprudencia y mientras no se hagan con la escrupulosidad debida los exámenes para los grados en las universidades y los de abogados en el Consejo, chancillerías y audiencias, no puede contarse con seguridad con la instrucción de los que se presentan con semejantes títulos y $\operatorname{grados}^{30}$.

El reconocimiento implícito de la imposibilidad de la Monarquía por establecer controles efectivos sobre la veracidad de las informaciones aportadas por los pretendientes es suficientemente esclarecedor tanto de las verdaderas limitaciones del aparato estatal para fijar criterios supuestamente objetivos para seleccionar su personal como, en el marco de este expediente, del argumento básico utilizado por los informantes para suprimir tales disertaciones llevándose por delante también «los requisitos de diez años de estudios, inclusos quatro de práctica» $\mathrm{y}$ «la informacion de vita et moribus ${ }^{31}$. Es indudable que tal resolución final, más allá del condicionamiento de la opinión vertida por el monarca y de la imposibilidad de verificación de la documentación aportada, supone un retraso en la profesionalización técnica de los corregidores, pero dentro de las opiniones vertidas conviene destacar los elementos novedosos aportados por Benito Ramón Hermida, no presentes en el informe de Codina e ignorados en la consulta de la Cámara y en la real cédula de noviembre.

Más allá de que puedan ser interpretados como modernizadores, Hermida es el único que se acerca a un intento efectivo de controlar la información aportada por los pretendientes, único camino posible para dar más importancia a la capacidad técnica, a la naturaleza letrada del cargo. Así, pone ejemplos de control efectivo de las capacidades a través de «exámenes generales» realizados «en algunos países», «en los concursos a curatos de Toledo y otras partes» o en los exámenes que se realizaban para las plazas dotales que sitúa en tiempos del Felipe $V$ asegurando que

mas si en la extensión de un gran reyno se juzga dispendioso este proyecto para pretendientes, a lo menos, ya que no sea posible hacer de otra suerte un verdadero juicio comparativo entre ellos, es inevitable asegurarse de su capacidad absoluta por medio de algunos exercicios públicos y trabajos literarios, en que no quepa error de la persona que los hace, encargando este cuidado y su debida censura, en la Corte a las Academias práctica que hay en ella y en las provincias a las que subsisten en las audiencias y Universidades o a los Colegios de abogados respectivos, según la instrucción que sobre esto podrá formarse $\mathrm{e}^{32}$.

30. AHN, Cons., leg. 13.291.

31. Artículo II de la Real Cédula de 7.11.1799.

32. AHN, Cons., leg. 13.291.

(C) Ediciones Universidad de Salamanca / ®@ Stud. his., H. ${ }^{a}$ mod., 39, n. 1 (2017), pp. 229-262 
MANUEL AMADOR GONZÁLEZ FUERTES

¿EL HÁBITO HACE AL MONJE? INSTITUCIONALIZACIÓN DE LA CARRERA JUDICIAL EN ESPAÑA A FINALES DEL ANTIGUO RÉGIMEN

La perspectiva de Domingo Codina, sin embargo, es completamente diferente al minusvalorar esta formación práctica que acepta como falsa pero que no le preocupa apelando a un «concepto público superior» que, por otra parte no define:

En todos los colegios, cuerpos literarios y aún en los tribunales sucede lo mismo: tan cierto parece que el crédito y concepto público son el berdadero medio de graduar a los sugetos ${ }^{33}$.

La consecuencia que deriva de tal afirmación-«no son necesarias en el concepto fiscal muchas leyes reglamentarías»-puede resultar sorprendente a nuestros ojos pero el fiscal apelará a otros valores también presentes en la concepción tradicional de la servidumbre regia:

El amor al soberano, el deseo del bien público y la constante adhesión a la justicia en las personas encargadas de proponer a su Majestad sugeto para los empleos, serán en todo tiempo los más seguros garantes de las buenas y acertadas elecciones que no es posible circunscribir a reglas tan precisas ni acaso sería combenientes, quando lo fuese que no dejen lugar a un prudente y regulado juicio, digno de la confianza de su Majestad en las personas en que tiene a bien depositarla ${ }^{34}$.

Nos encontramos con un perfecto ejemplo de dos concepciones que, aunque resulten en el fondo contradictorias, actúan de manera complementaría en el imaginario ilustrado. Este es el enfrentamiento de fondo, resuelto por el poder omnímodo del rey en la Cédula de 7 de noviembre de 1799 apostando por la no regulación de las capacidades técnicas. El primer intento de avanzar en tal sentido, con todas las limitaciones que se quiera, representado por la presentación de disertaciones será abortado en 1799 para no resurgir en el Antiguo Régimen y quizá explique las causas del rechazo del dictamen de Hermida por la propia Cámara, más allá de su gran extensión y de su carácter un tanto pedantesco y disgresivo.

Aunque, evidentemente, a lo largo de este período aparecen otras normas que regulan la justicia de primera instancia de la Monarquía ${ }^{35}$, la Cédula de

33. Ibidem.

34. Ibidem.

35. Algunas recogidas por Guardiola (Guardiola y SÁEz, L.: El corregidor perfecto, y juez dotado de las calidades necesarias y convenientes para la recta administración de Justicia, y buen gobierno politico y económico de los Pueblos; y avisado muy particularmente, entre otras cosas, de las muchas cargas y obligaciones de su oficio, con expresión de algunos medios ó reglas para defenderse jurídicamente en el juicio de residencia, sindicato ó capitulacion: conforme todo á las Leyes divinas, Derecho Real de España, y Reales resoluciones hasta abora publicadas sobre el nuevo método de proveerse y servirse los Corregimientos y Alcaldias Mayores del Reyno, asi de Realengo y Ordenes Militares, como de Señorío. Madrid, 1796, pp. 140-144). Conviene

(C) Ediciones Universidad de Salamanca / ®@ Stud. his., H. ${ }^{a}$ mod., 39, n. 1 (2017), pp. 229-262 
MANUEL AMADOR GONZÁLEZ FUERTES

¿EL HÁBITO HACE AL MONJE? INSTITUCIONALIZACIÓN DE LA CARRERA JUDICIAL EN ESPAÑA A FINALES DEL ANTIGUO RÉGIMEN

noviembre de 1799 completará la normativa más significativa para regular las «carrera de varas» de la Monarquía en sus territorios penínsulares. Habrá que esperar a la restauración fernandina en 1814 para la aparición de otra Real Cédula, de 30 de junio de 1814, por la que el monarca declarará:

Sin perjuicio de lo que á su tiempo se resuelva en el expediente sobre el decreto de las Cortes en punto á señoríos particulares, me reservo por ahora el nombramineto á consulta de la Cámara de los Corregimientos y Alcaldes mayores en los pueblos de señorío que antes los tenian ${ }^{36}$.

Se completaba así la tendencia anterior de igualar a los jueces realengos con los señoriales pues el «expediente sobre el decreto de las Cortes» no llegó nunca a resolverse. A los efectos aquí considerados esta disposición resulta significativa por el enorme incremento de corregidores y alcaldes mayores que tal resolución propició pues, con solo esta medida, el número de los mismos se duplicó ampliamente dando un nuevo impulso, a efectos prácticos, del carácter letrado de estos servidores del rey, lo que conllevó la definitiva supresión, ya comentada, de los corregimientos políticos en 1833 que no llegó a tener grandes efectos prácticos.

\section{LA PRODUCCIÓN INTELECTUAL: LA UTOPÍA DEL «CORREGIDOR PERFECTO»Y LA REALIDAD PRÁCTICA}

A lo largo de los reinados de Carlos III y de Carlos IV de manera no coordinada y a consecuencia de los motines de 1766, aunque con el trasfondo de las ideas reformistas y racionalizadoras de los ilustrados más conspicuos, se llevaron a cabo toda una serie de reformas en la administración de justicia que pasaron, entre las medidas más cercanas a las instituciones judiciales de la Monarquía, por la creación de una nueva recapitulación de la legislación real -la Novísima Recopilación-, la mejor difusión de la misma a través de la edición de obras anuales como los Prontuarios de Severo Aguirre y José Garriga antes de la Guerra de la Independencia y la llamada Colección legislativa tras la misma y reformas en diferentes tribunales territoriales. Dentro de este marco general es donde hay que introducir las reformas legales analizadas en el capítulo anterior de los corregimientos y alcaldías mayores

destacar la Cédula de 24.1.1787 por la que pretende «que en las Varas de Señorío guarden los dueños jurisdiccionales, y los Alcaldes Mayores de sus respectivos Pueblos las reglas, tiempos y demás calidades resueltas para las de Realengo».

36. Martín de Balmaseda, F.: Decretos del rey don Fernando VII. Año primero de su restitución al trono de las Españas. Se refieren todas las reales resoluciones generales que se han expedido por los diferentes ministerios y consejos desde 4 de mayo de 1815 hasta fin de diciembre de igual año. Madrid, 1816. pp. 149-152. La cita, en p. 152.

(C) Ediciones Universidad de Salamanca / ®@ Stud. his., H. ${ }^{a}$ mod., 39, n. 1 (2017), pp. 229-262 
y la creación de la «carrera de varas», como una parte dentro de la organización de la administración judicial ilustrada.

Pero tal reforma general, con una vaga idea general tendente a la capacitación especializada, se debe incluir en una reforma global del mundo de la judicatura que debía comenzar por la educación. Al albur de las reformas educativas proyectadas por los gobernantes, en el campo del derecho resultaba fundamental para los gobernantes reforzar el conocimiento del derecho de la Monarquía en las universidades. La marginación del derecho real en los planes de estudios universitarios será uno de los puntos más criticados por los intelectuales intentando incorporarlos en los diferentes planes de estudios universitarios elaborados y aprobados por los gobernantes ${ }^{37}$. Aunque su éxito fue limitado, también se observa que tales materias de derecho patrio se incorporaron, fuera de lo que se podía denominar el curriculum oficial, a través de las diferentes academias que se crearon durante el siglo xviII.

Esta formación difusa, apoyada por la Monarquía pero no dependiente de ella, partía del cuerpo social y se desarrollaba en las grandes ciudades, localidades con tribunales reales (audiencias y chancillerías) y sedes universitarias. Aunque sus resultados no alcanzaron a paliar la escasa formación de los estudiantes y licenciados, fue una de las escasas vías para adquirir este tipo de conocimientos, junto con los cursos que se fueron implantando en algunas universidades, la literatura jurídica y las prácticas desempeñadas como abogados en los reales tribunales.

Estos nuevos caminos de la educación jurídica se vinculan a una mejor preparación jurídica para los nuevos corregidores y alcaldes mayores pero, a la vez, incidirán también en la especialización de otras competencias también incluidas en las competencias de un corregidor o de un alcalde mayor (el desarrollo del concepto de policía o la especialización de temas hacendísticos no tan dependientes del nuevo cargo de intendente como la historiografía cree por la ausencia práctica de personal) lo que suponía, a nivel práctico, una limitación en la especificidad judicial que albergaban los cambios legislativos y que, ante la negativa del poder a separar las competencias del delegado regio en el ámbito local, imposibilitaron el desarrollo de tal especificidad en una contradicción desde nuestra visión actual, pero que puede ser explicable si se considera que lo que se pretendía no era tanto un cambio de la «segunda naturaleza» del juez ordinario como el añadido de capacidad técnica letrada.

En la configuración de la naturaleza de los corregidores y alcaldes mayores la producción intelectual generada alrededor de las nuevas disposiciones se centrará

37. Peset Reig, M.: «Derecho romano y Derecho real en las universidades del siglo XvinI», Anuario de Historia del Derecho Español, XLV, 1975, pp. 273-339.

(C) Ediciones Universidad de Salamanca / ®@ Stud. his., H. ${ }^{a}$ mod., 39, n. 1 (2017), pp. 229-262 
MANUEL AMADOR GONZÁLEZ FUERTES

¿EL HÁBITO HACE AL MONJE? INSTITUCIONALIZACIÓN DE LA CARRERA JUDICIAL EN ESPAÑA A FINALES DEL ANTIGUO RÉGIMEN

en tres focos de atención: la literatura sobre la gobernación local publicada, las lecciones que sobre esta problemática desarrollaron las diferentes academias prácticas y, muy vinculada con la anterior, la propia producción de los aspirantes a los juzgados ordinarios a través de las disertaciones, obligatorias entre 1783 y 1799; y tendrá dos objetivos básicos: la configuración de un teórico «corregidor perfecto» y la ayuda práctica para desarrollar las labores a desempeñar en los cargos o para el acceso a los mismos. Pero no hay que considerar ambos objetivos en términos de enfrentamiento o contradicción. Nos encontramos ante las dos caras de una misma moneda. La producción intelectual se encamina a una misma finalidad, crear un juez ordinario homogéneo, tanto desde el punto de vista de su teórica naturaleza ideal, como desde la realidad práctica del desempeño de sus funciones.

Nos moveremos ahora en el territorio de la educación en donde se pretende tanto la asimilación supraestructural de los ideales defendidos por el poder en función de la legislación aprobada como la homogeneización infraestructural de las formas de desempeño a través de la trasmisión de una serie de conocimientos prácticos que ayuden a un desempeño similar de sus atribuciones. En otras palabras, a un intento de imposición de la naturaleza teórica del corregimiento (¿qué es?) y de la forma de desarrollar tal labor (¿cómo actúa?).

En el primer terreno, en el que se reflexiona sobre qué es un corregidor, nuestra fuente básica no puede ser otra que el libro de Guardiola sobre el corregidor perfecto y en él se observará, como ya ocurría anteriormente en la aproximación de Santayana ${ }^{38}$, la larga sombra del clásico absoluto sobre la materia, la Política para corregidores de Castillo de Bobadilla ${ }^{39}$.

Es probable que el éxito de la primera edición de El corregidor perfecto en $1785^{40}$ ayudase a Lorenzo Guardiola y Sáez a conseguir el cargo de Agente Fiscal del Consejo de Castilla, que ejercerá por lo menos desde noviembre de $1788^{41}$. Pero de lo que parece que sí podemos estar seguros es del éxito de la obra, que

38. Santayana Bustillo, L. de: Govierno político de los pueblos de España, y el corregidor, alcalde, juez de ellos. Zaragoza, 1742.

39. Castillo de Bobadilla, J.: Política para corregidores y señores de vassallos, en tiempo de paz y de guerra, y para Iuezes Ecclesiasticos y Seglares, y de Sacas, Aduanas, y de Residencias, $y$ los Oficiales y para Regidores, y Abogados: $y$ del valor de los Corregimientos, $y$ Goniernos Realengos y de las Órdenes. Madrid, 1597, 2 vols.

40. Guardiola y Sáez, L.: El corregidor perfecto, y juez exactamente dotado de las calidades necesarias y convenientes para el buen Gobierno Económico y Político de los Pueblos, y la mas recta administración de Justicia en ellas; $y$ avisado, entre otras cosas, de las muchas cargas y obligaciones de su Oficio: conforme todo á las Leyes Divinas, Derecho Real de España, y Reales Resoluciones hasta ahora publicadas sobre la nueva Planta y Escala admirable de los Corregimientos y Alcaldías Mayores de estos Reynos. Madrid, 1785.

41. AHN, Cons., leg. 5.547, exp. 50.

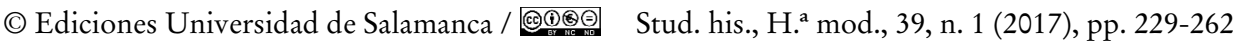


alcanzó una segunda edición en 1796 publicitada como «notablemente adicionada y enriquecida» $\mathrm{y}$ en donde, más allá de algunas ampliaciones no muy significativas en el texto, se incluiría una dedicatoria al marqués de Astorga, Vicente Joaquín Osorio de Moscoso, y la Instrucción para corregidores y alcaldes mayores de $1788^{42}$. La inclusión de esta Instrucción justificaría con creces la puesta al día del libro que tendría entre sus dos objetivos básicos, el otro era llevar a cabo una reflexión sobre la naturaleza ideal del cargo, el de ofrecer una recopilación de los cambios legislativos sobre los dos oficios iniciados con las normas de $1783^{43}$.

Igual que objetivos, el libro tiene dos partes bien diferenciadas debidas a las vicisitudes de su realización: una primera en la que el autor se esfuerza por caracterizar al autoproclamado «corregidor perfecto» y una segunda en donde se incluyen las nuevas disposiciones normativas. Una primera lectura puede resultar algo decepcionante. La caracterización ideal del juez no pasa, a pesar de la afirmación del prólogo «que para que el Corregidor ó Alcalde sea qual conviene para la buena administracion de Justicia y gobierno de los Pueblos, ademas de ser buen Letrado, pues sin las Leyes no pueden juzgar bien los pleytos y controversias

42. La tramitación de una segunda edición se inició después de la publicación de la Instrucción de corregidores de 15 de mayo de 1788. La instancia para la censura se presentó antes de 5 de noviembre de 1788, ese día la Sala de Gobierno del Consejo encomendó la censura al Colegio de Abogados de Madrid que emitió un informe favorable, firmado por Juan Antonio Avella Menéndez, Nicolás Nieto de Lindoso, Tomás Sánchez Villaseñor, Bartolomé Jimeno, Miguel Osteret y Herrera, Juan Morón y Domingo Rodríguez Rosales, el primero de diciembre de dicho año. El 6 de diciembre de 1788 la Sala de Gobierno resolverá afirmativamente (AHN, Cons., leg. 5.547, exp. 50).

43. Conviene hacer una pequeña descripción de las vicisitudes de su realización de las que nos informa su expediente de censura (AHN., Cons. Leg. 5.547, Exp. 50). Guardiola presentó un primer texto antes del 22 de agosto de 1783 pues en esta fecha la Sala de Gobierno del Consejo Real acordó remitir el original al Colegio de Abogados de Madrid para que realizase la correspondiente censura. Sin embargo, antes del 5 de mayo de 1784 Guardiola solicita la devolución del original para introducir las modificaciones legislativas aprobadas tras la finalización de su texto. Del 11 de mayo de 1784 hasta principios de julio trabajó en la realización de los apéndices presentándolo de nuevo a censura ante el Colegio de Abogados de Madrid por nuevo acuerdo de la Sala de Gobierno de 10 de julio. Un año después el Colegio de Abogados, el 27 de julio de 1785, emite un informe positivo, firmado por Mateo Alonso de Prado, Miguel Isidro Hernanz López, Santiago Domínguez, Francisco de Cangas, Juan Antonio Mella Menéndez, Juan José Barea y Ortiz, Ignacio de Estefanía y Juan Morón, en estos términos: «Halla que sobre no contener la obra proposición contraria a el Dogma, regalías de su Majestad y buenas costumbres, desempeña su autor el título con sana doctrina y claridad y le parece al Colegio que es útil sin embargo de los varios tratados que ay de esta clase, tanto por su brevedad quanto por comprender las nuevas reales instruziones y reglamentos en la materia de que trata los que no pudieron tener presentes los que escrivieron antes de su publicación y que por lo mismo se le puede conceder la licencia que solicita para imprimirla». Con este informe la Sala de Gobierno aprobará la impresión el primero de agosto de 1785.

(C) Ediciones Universidad de Salamanca / ®@ Stud. his., H. ${ }^{a}$ mod., 39, n. 1 (2017), pp. 229-262 
MANUEL AMADOR GONZÁLEZ FUERTES

¿EL HÁBITO HACE AL MONJE? INSTITUCIONALIZACIÓN DE LA CARRERA JUDICIAL EN ESPAÑA A FINALES DEL ANTIGUO RÉGIMEN

de los hombres» ${ }^{44}$, de un resumen de la Política para corregidores de Castillo de Bovadilla, trufado de una sucesión de notas a pie de página en donde el joven letrado trata de demostrar su valía intelectual:

Que estos Magistrados y Padres de la República que gobiernan sean sobrios, modestos, agradables, benignos, corteses y afables. No iracundos, altivos, ni crueles, ó sobradamente duros y severos con los subditos, graves, templados y mesurados, asi en el gesto, pasos y palabras; como en el aseo, adorno y compostura de sus personas: no muy habladores ni jactanciosos de sí mismos, cautos, no sequaces de los errores de sus antecesores: no pomposos ó presuntuosos, persuadiéndose que todo se lo saben, y despreciando los buenos consejos: ni noveleros, esto es, amigos de hacer novedades, alterando los buenos usos y costumbres de sus respectivos Pueblos, o estableciéndolas de nuevo sin causa ni utilidad pública: ni precipitados, ó negligentes en sus determinaciones: ni fáciles, ó sobradamente incrédulos: sean recatados, y no sospechosos ni maliciosos, ni hagan profesión de ser astutos: sean castos: no dados á convites, especialmente privados: ni tengan amistades estrechas, mayormente en los Pueblos de bandos y parcialidades, excusándose de juegos, bayles y otros pasatiempos impropios de sus Oficios: no sean orgullosos, austeros, ni muy tristes y melancólicos, acomodando el propio genio al de los subditos: no extremados, ni singulares en sus deliberaciones; y en fin, que su principal intento sea el bien común de la República, el cuidado de los abastos públicos, la observancia de las Leyes, y el amparo de los subditos, sin olvidarse del socorro de los pobres, del amor de los huérfanos, de la veneración de los Templos, de la protección de las virtudes, y del breve despacho de los negocios y querellas, juzgando siempre lo justo sin distinción de personas: cuidando asimismo de la fidelidad, diligencia, limpieza, y bondad de los Alguaciles ${ }^{45}$.

Nada nuevo bajo el sol. La influencia de Castillo de Bobadilla, cuya obra había tenido una reciente reedición por la Imprenta Real en $1775^{46}$, era demasiado poderosa como para presentar una alternativa en donde cupiese el cambio hacia la mayor importancia de la naturaleza letrada. La novedad no se encontraba en la caracterización del juez, ni siquiera en la recopilación legislativa de la segunda parte, que tampoco explicaría su éxito, pues el desarrollo editorial no hacía difícil

44. Guardiola y Sáez, op. cit., p. VII.

45. Guardiola y SÁEz, op. cit., pp. 86-88. No por otras características morales define Santayana a sus corregidores a la altura de 1742 valiéndose, también de las opiniones de Bobadilla (Santayana Bustillo, op. cit., p. 165).

46. Castillo de Bobadilla, J.: Política para corregidores y señores de vasallos, en tiempo de paz, y de guerra, y para prelados en lo espiritual, y temporal entre legos, Jueces de Comisión, Regidores, Abogados, y otros Oficiales Públicos: y de las Jurisdicciones, Preeminencias, Residencias, y salarios de ellos: $y$ de lo tocante á las Ordenes y Caballeros de ellas. Madrid, 1775, 2 vols.

(C) Ediciones Universidad de Salamanca / ®@ Stud. his., H. ${ }^{a}$ mod., 39, n. 1 (2017), pp. 229-262 
MANUEL AMADOR GONZÁLEZ FUERTES

¿EL HÁBITO HACE AL MONJE? INSTITUCIONALIZACIÓN DE LA CARRERA JUDICIAL

EN ESPAÑA A FINALES DEL ANTIGUO RÉGIMEN

la recopilación de las disposiciones. La verdadera novedad del libro radicaba en otro punto que sí podía ser de utilidad para los pretendientes:

Yo prescindo por ahora del mérito de estas obras [la Política de Castillo y el Gobierno de Santayana] (qué tengo en mi estudio como buenas); pero no puedo menos de decir, que ambas contienen muchas cosas y autoridades que hoy ya no rigen; $\mathrm{y}$ al contrario carecen de otras muchas que al presente son de rigorosa observancia en los asuntos que tocan, cuyos extremos viciosos por exceso y por defecto, aunque inculpables, omito referir ${ }^{47}$.

Recopilar y aclarar la legislación vigente era el camino propuesto por Guardiola, lo que implicó, en el desarrollo del libro, un cuidado especial en la redacción de las notas que glosaban los contenidos. Los primeros capítulos, que tratan sobre la justicia y la caracterización de los corregidores, no escapan de la erudición doctrinal y legislativa, pero a parte de la «Parte tercera» sobre los juicios de residencia el contenido de las notas se diferencia claramente. Empiezan a escasear los autores clásicos y se incrementa la legislación novedosa, no solo la derivada de la Nueva Recopilación o de los Autos Acordados del Consejo de Castilla. Y lo mismo ocurre en las glosas que acompañan a la recopilación legislativa de la «Parte quarta». De manera condensada, aunque no sistemática, el pretendiente a varas tenía a su alcance, a un precio módico, un actualizado compendio de referencias legislativas a las que acudir a la hora de preparar su incorporación a la carrera de varas.

Esta utilidad interesa en nuestros propósitos, pues ayuda a configurar esta «segunda naturaleza» de la que venimos hablando, no a través de un proceso de caracterización del juez ideal, como sería en un principio de suponer, sino al delimitar lo que en la práctica debe o no debe hacer el servidor regio. El caso de la «Parte tercera», dedicada a los juicios de residencia, resulta muy ilustrativo. A lo largo de sus páginas Guardiola normativiza las funciones que van a ser inspeccionadas y las relaciona con la legislación contemporánea correspondiente, lo que, a la par de resultar útil para el corregidor o alcalde mayor residenciado, homogeneiza el proceso y el modo que tiene que actuar el juez en el mismo creando pautas de comportamiento comunes que al interiorizarse crean el «habitus».

Esta misma función normativa cumple la literatura jurídica contemporánea que se centra no en el terreno doctrinal o de reflexión filósofica del derecho, sino en la práctica jurídica de tribunales y juzgados que había alcanzado ya un significativo desarrollo durante el reinado de Carlos III y se desarrollará más a partir de 1783. Aquí es donde deben incluirse los grandes, por extensos, trabajos como

47. Guardiola y Sáez, op. cit., p. XI.

(C) Ediciones Universidad de Salamanca / ®@ Stud. his., H. ${ }^{a}$ mod., 39, n. 1 (2017), pp. 229-262 
MANUEL AMADOR GONZÁLEZ FUERTES

¿EL HÁBITO HACE AL MONJE? INSTITUCIONALIZACIÓN DE LA CARRERA JUDICIAL EN ESPAÑA A FINALES DEL ANTIGUO RÉGIMEN

la Práctica universal forense de Francisco Antonio de Elizondo con su Apéndice, el Código y práctica criminal arreglado a las leyes de España de Vicente Vizcaíno Pérez, la Librería de jueces y sus Adicciones de Manuel Silvestre Martínez y Ramón Antonio de Higuera e incluso las diferentes Librerias de José Febrero, todos con ediciones posteriores a 1783. A través de estos «manuales» de procedimientos se pretendía facilitar la labor de los jueces, no solo corregidores y alcaldes mayores, al proporcionarles una guía de actuación pero, al mismo tiempo y de manera más o menos consciente, la semejanza en la tramitación proporcionaba una determinada manera de enfocar los negocios, unas normas de comportamiento.

Aunque el éxito de estas publicaciones se podía entender, como era el caso de Benito Ramón Hermida en el informe fiscal citado, como una puerta abierta a la dejadez del juez que acude a las fórmulas estereotipadas de estos libros para reducir su trabajo:

Aquellos cortos pueblos [los de los primeros destinos de corregidores y alcaldes mayores] carecen, por lo común, de gentes háviles con quienes tratar, faltan libros a que acudir y toda la Biblioteca del Juez está reducida a la librería de Juezes, Febrero, Elizondo y otros semejantes auxilios de la araganería que produxo el presente tiempo ${ }^{48}$.

Era ver el vaso medio vacío pero la utilización de estos «manuales» también fomentaba una manera común de tramitar los procesos y con ello, poco a poco, un modo peculiar y similar de entender su trabajo y autoexplicarse.

Abandonamos el Antiguo Régimen con la última aportación significativa sobre los corregidores y alcaldes mayores, la exhaustiva y relativamente olvidada obra de Manuel Ortiz de Zúñiga y Cayetano de Herrera ${ }^{49}$ sobre los Deberes

48. AHN, Cons., leg. 13.291.

49. En 1832 eran dos jóvenes letrados que se presentaban como abogados de los Reales Consejos, del Colegio de Sevilla y Fiscal de Marina de la provincia de Sevilla (Ortiz de Zúñiga) y del Colegio de Cádiz (Herrera). Ortiz de Zúñiga llegará a ser uno de los menos conocidos pero más prolíficos jurisconsultos del Partido Moderado con una extensa obra caracterizada por su carácter recopilador llegando a la Presidencia de Sala del Tribunal Supremo. Herrera tendrá menos éxito pues sus ascensos solo le permitirán ocupar la Presidencia de la Sala Tercera de la Audiencia de Sevilla. El hecho de que Herrera no siguiese una carrera literaria y que Ortiz de Zúñiga siete años después publicase una obra similar de la administración de justicia liberal (ORTIZ DE ZÚÑIGA, M.: Biblioteca judicial, ó tratado original y metódico de cuanto hay vigente en la legislación, y en la práctica con relación á los juzgados de primera instancia. Madrid, 1839), ampliada un año después a las audiencias y al Tribunal Supremo (ORTIZ DE ZúÑIgA, M.: Biblioteca judicial. Parte tercera, en que se contienen la organizacion y atribuciones de las audiencias y del Tribunal Supremo de Justicia. Madrid, 1840), puede predisponernos a considerar que tuviera una parte más activa en los Deberes y atribuciones.

(C) Ediciones Universidad de Salamanca / ®@ Stud. his., H. ${ }^{a}$ mod., 39, n. 1 (2017), pp. 229-262 
MANUEL AMADOR GONZÁLEZ FUERTES

¿EL HÁBITO HACE AL MONJE? INSTITUCIONALIZACIÓN DE LA CARRERA JUDICIAL

EN ESPAÑA A FINALES DEL ANTIGUO RÉGIMEN

$y$ atribuciones de los correjidores, justicias y Ayuntamientos de España ${ }^{50}$, cuyo primer tomo salió a la luz en abril de 1832. La obra tuvo la mala fortuna de ver la luz dos años antes de que el sistema administrativo de la Monarquía absoluta fuese sustituido por el liberalismo triunfante lo que provocó que, a pesar de una buena primera acogida que propicio la aparición de un Apéndice $e^{51}$ en 1833, se diluyese en un olvido derivado de su falta de utilidad en el nuevo orden que, paradójicamente, era su primitivo objetivo.

Quejosos de la falta de exhaustividad de Guardiola, reticentes a regresar a Castillo de Bobadilla, pues su antigüedad le hacía poco útil para sus fines, los autores se afanan en la recopilación minuciosa, hasta alcanzar los cuatro tomos, de las competencias y procedimientos a desarrollar por jueces y ayuntamientos en sus cometidos soslayando intencionadamente cualquier valoración sobre el oficio de corregidor o alcalde mayor aunque, al final, en el Apéndice, parece como si se hubieran visto obligados a reconocer el peso de la tradición de Castillo de Bobadilla introduciendo en unas «Observaciones preliminares» un breve resumen de la caracterización que este hizo del cargo de corregidor a finales del siglo $\mathrm{xvI}^{52}$.

Si consideramos la posterior carrera judicial, política y literaria de Ortiz de Zúñiga los Deberes y atribuciones podrían pasar como un claro ejemplo, frustrado por los cambios de la organización administrativa, de «positivismo» recopilatorio decimonónico, pero si el punto de vista se establece desde la posición en 1832 de dos jóvenes abogados que están intentando abrise camino en la «carrera de varas», una obra de estas características se vincularía más con las recopilaciones ilustradas antes citadas en donde la exhaustividad rendiría sus frutos en el avance en la carrera judicial y también explicaría la obligación de rendir el debido tributo a Castillo de Bobadilla, pero ya en el Apéndice, tras un buen recibimiento. Vistas así las cosas, y teniendo también en cuenta la tradicción recopilatoria de la ciencia jurídica -una de sus necesidades imprescindibles- y la influencia ilustrada en el moderantismo hispano -a través, aunque no solo, de la importancia del elemento afrancesado- no nos parece alejarnos mucho, en el tema que ahora tratamos, de las recopilaciones antedichas aunque, eso sí, la reticencia en un primer momento a la conceptualización del cargo desde planteamientos morales revela una nueva manera de ver las cosas.

50. Ortiz de ZúÑiga, M. L. y Herrera, C. de: Deberes y atribuciones de los correjidores, justicias y ayuntamientos de España. Madrid, 1832, 4 vols.

51. Ortiz de Zúñiga, M. L. y Herrera, C. de: Apendice a la obra titulada deberes y atribuciones de los correjidores, justicias y ayuntamientos de España. Madrid, 1833.

52. Ortiz de ZúÑiga y Herrera, op. cit., pp. 7-18.

(C) Ediciones Universidad de Salamanca / ®@ Stud. his., H. ${ }^{a}$ mod., 39, n. 1 (2017), pp. 229-262 
Pero la producción libresca no era la única fuente intelectual al alcance de los pretendientes o de los corregidores y alcaldes mayores. El desarrollo de las academias de jurisprudencia a lo largo del reinado de Carlos III creó un ámbito de sociabilidad en el que se conseguía reconomiento público, relaciones sociales e, incluso, intercambio cultural ${ }^{53}$. Ya hemos remarcado el carácter complementario de la enseñanza que pudiera darse en estas academias, enfocada más hacia los conocimientos prácticos y el derecho real de la Monarquía ${ }^{54}$. La afortunada coincidencia de la publicación en 1784 del Memorial literario, donde se daba información de sus actividades en la Corte nos permitirá saber si los temas relacionados con corregimientos y alcaldías mayores estaban entre los tratados en sus sesiones de trabajo. La revisión de los números correspondientes a los dos primeros años de la publicación, 1784 y 1785 (desde mediados de ese año la información aportada no es sistemática, pues los redactores recogían un resumen de alguna de las lecciones), nos permite comprobar que el servidor regio delegado en las ciudades sí estaba entre sus preocupaciones. Centrándonos exclusivamente en las lecciones más relacionadas con ellos se puede establecer el siguiente cuadro ${ }^{55}$ :

CuAdro 1: Lecciones sobre corregimientos y alcaldías mayores recogidas en el Memorial literario.

\begin{tabular}{|l|l|c|}
\hline \multicolumn{1}{|c|}{ Autor } & \multicolumn{1}{|c|}{ Contenido } & \multicolumn{1}{|c|}{ Memorial } \\
\hline $\begin{array}{l}\text { Pedro Navarro } \\
\text { del Valle }\end{array}$ & $\begin{array}{l}\text { «El Tribunal del Corregidor de Madrid y de sus dos Tenien- } \\
\text { tes» }\end{array}$ & $2.1784,50$ \\
\hline Bernardo Nadal & $\begin{array}{l}\text { «Los puntos de economía y policía, de que principalmente } \\
\text { ha de cuidar un Corregidor» }\end{array}$ & $3.1784,35-7$ \\
\hline Juan Rubio & $\begin{array}{l}\text { «La ciencia, probidad, desinterés, y demas calidades, que } \\
\text { deben concurrir en los Corregidores y Justicias, tomando } \\
\text { el argumento de los títulos 5 y 9 lib. 3. Recop. El capítulo } \\
\text { sexto de la Sabiduria: diligite lumen sapientiae omnes, qui } \\
\text { praeestis populis, y del \& ultimo Proem. Inst. Imper. \&, vos } \\
\text { metipsos, sic eruditos ostendite \&c.» }\end{array}$ & 4.1784, 56-9 \\
\hline
\end{tabular}

53. Para el ámbito de las academias sigue resultando fundamental la tesis doctoral de Antonio Risco: Risco, A.: La Real Academia de Santa Bárbara de Madrid (1730-1808). Toulouse, 1979, 2 vols.

54. La simple denominación de algunas ya denota estas características: Real Academia del Derecho Español y Público de San Isidro el Real, Real Academia de Jurisprudencia Práctica de San Isidro el Real, Academia de Jurisprudencia Teórico-Práctica de los Padres Menores del Espíritu Santo o Real Academia de Derecho Patrio y Público de San Felipe Neri.

55. El cuadro podría ampliarse si se hubieran recogido los temas que eran susceptibles de caer entre sus competencias.

(C) Ediciones Universidad de Salamanca / ®@ Stud. his., H. ${ }^{a}$ mod., 39, n. 1 (2017), pp. 229-262 
MANUEL AMADOR GONZÁLEZ FUERTES

¿EL HÁBITO HACE AL MONJE? INSTITUCIONALIZACIÓN DE LA CARRERA JUDICIAL EN ESPAÑA A FINALES DEL ANTIGUO RÉGIMEN

\begin{tabular}{|c|c|c|}
\hline Autor & Contenido & Memorial \\
\hline $\begin{array}{l}\text { José de } \\
\text { Covarrubias }\end{array}$ & $\begin{array}{l}\text { «Entre quiénes podrá considerarse mayor aptitud para } \\
\text { el desempeño de la Judicatura; si en aquellos que desde } \\
\text { luego que se recibieron de Abogados, se dedicaron á la } \\
\text { carrera de Corregidores, ó Alcaldes mayores; ó en los que } \\
\text { se incorporaron en los Colegios de Madrid, ó de alguna } \\
\text { Audiencia ó Chancillería, y exercieron la Abogacía» }\end{array}$ & $5.1784,20$ \\
\hline $\begin{array}{l}\text { Ignacio Noriega y } \\
\text { Robredo }\end{array}$ & $\begin{array}{l}\text { «S sería conveniente que todos los que hubiesen de dedicarse } \\
\text { á la Judictura estudiasen la Práctrica de las leyes en la Corte } \\
\text { ó en los Pueblos donde hay Audiencia ó Chancilleria, y si } \\
\text { aun sería útil estender esta providencia á los Abogados» }\end{array}$ & $9.1784,14-7$ \\
\hline Antolín Villafañe & $\begin{array}{l}\text { «Si convendrá establecer, que los Corregidores ó Alcaldes } \\
\text { Mayores no pudiesen dar sentencia alguna difinitiva sin } \\
\text { asistencia y consejo de hombres buenos ó Letrados que les } \\
\text { sirviesen de consejeros, como estaba prevenido por Leyes } \\
\text { Reales para los Adelantados» }\end{array}$ & $10.1784,19$ \\
\hline $\begin{array}{l}\text { Juan de Dios del } \\
\text { Peche }\end{array}$ & $\begin{array}{l}\text { «Las notorias ventajas que se siguen al Reyno del } \\
\text { establecimiento de clases en los Corregimientos, y duración } \\
\text { de seis años en cada uno; y las providencias dadas, y que } \\
\text { pudieren darse para impedir las leyes, que mandaban fuese } \\
\text { sdu duracion de un aó, o lo mas dos» }\end{array}$ & $10.1784,25$ \\
\hline $\begin{array}{l}\text { Agustín Plácido } \\
\text { Zanon }\end{array}$ & $\begin{array}{l}\text { «Las ventajas que ofrece la escala de Corregimientos } \\
\text { nuevamente establecida: si esta ley política puede tener ó } \\
\text { no influencia en la felicidad de los Pueblos, y proporcionar } \\
\text { sin perjuicio alguno la buena administración de justicia» }\end{array}$ & $11.1784,22$ \\
\hline Francisco Borbón & $\begin{array}{l}\text { «Que medio podria darse para que en caso de opresion, ya del } \\
\text { Corregidor, ó ya de algun poderoso, á quien este diese favor } \\
\text { por muy infeliz que fuese el vasallo oprimido, consiguiera } \\
\text { prontamente el desagravio» }\end{array}$ & $11.1784,24-5$ \\
\hline Benito José López & $\begin{array}{l}\text { «a provisión que contiene la instruccion de Corregidores, } \\
\text { de que estos en el territorio de su jurisdiccion, no puedan } \\
\text { comprar heredad, ni tampoco edificar casa sin licencia del } \\
\text { Rey, ni comerciar, ni traer ganado en su propio término» }\end{array}$ & $11.1784,46-9$ \\
\hline $\begin{array}{l}\text { Manuel de } \\
\text { Palacios }\end{array}$ & «Las calidades que deben tener los Corregidores» & $12.1784,20-1$ \\
\hline $\begin{array}{l}\text { Pedro Garballón } \\
\text { de Iturbide }\end{array}$ & $\begin{array}{l}\text { «El origen, necesidad y objeto del oficio de Corregidor en } \\
\text { España» }\end{array}$ & $12.1784,21-2$ \\
\hline $\begin{array}{l}\text { Domingo Zaporta } \\
\text { y Valls }\end{array}$ & $\begin{array}{l}\text { «a obligacion que tienen los Corregidores de visitar cada } \\
\text { tres años todo el territorio de su jurisdiccion, manifestado } \\
\text { quáles objetos deben especialmente proponerse en tales } \\
\text { visitas; como la Agricultura y las Fábricas, y las ventajas } \\
\text { naturales del territorio para el Comerio, las debe observar el } \\
\text { Corregidor, mejorando la cultura é industria de sus subditos» }\end{array}$ & $1.1785,78-80$ \\
\hline
\end{tabular}


MANUEL AMADOR GONZÁLEZ FUERTES

¿EL HÁBITO HACE AL MONJE? INSTITUCIONALIZACIÓN DE LA CARRERA JUDICIAL EN ESPAÑA A FINALES DEL ANTIGUO RÉGIMEN

\begin{tabular}{|l|l|l|}
\hline Andrés del Río & $\begin{array}{l}\text { «La obligación que tienen los Corregidores de hacer que los } \\
\text { Caminos ó Campos de las Ciudades ó Villas estén segurós; } \\
\text { y hasta donde alcanzan sus facultades y jurisdiccion para } \\
\text { el desempeno de un óbjeto tan importante á la seguridad } \\
\text { pública, al Comercio, y á la Poblacion» }\end{array}$ & 5.1785, 77-82 \\
\hline $\begin{array}{l}\text { José Ignacio } \\
\text { Llorens y Peguera }\end{array}$ & $\begin{array}{l}\text { «La obligacion que tienen los Corregidores de visitar las } \\
\text { Ventas y Mesones en los respectivos distritos de su jurisdi- } \\
\text { cion, y encargo que les hacen las leyes del Reyno para que } \\
\text { cuiden ó procuren el que las tales Ventas ó Posadas sean } \\
\text { cómodas, y esten bien abastecidas de lo que necesitan los } \\
\text { caminantes» }\end{array}$ & 12.1785,494-500 \\
\hline
\end{tabular}

Fuente: Memorial literario, instructivo y curioso de la Corte de Madrid. núms. I-XXIV, 1784-1785.

Desgraciadamente solo contamos con un breve resumen de tres de las conferencias, las pronunciadas por Juan Rubio, Ignacio Noriega y Pedro Garballón. En los tres casos subyace, como no podía ser de otra forma, la importancia de la formación letrada en el uso de las atribuciones de los jueces. Así, para Juan Rubio «para que en la actual constitución de España puedan los Jueces cumplir exactamente con su Ministerio, y proporcionar al Reyno los adelantamientos y ventajas de que es capáz, deben instruirse en el Derecho comun y patrio, usos y costumbres de sus naturales, en la Policía, historia de la Nacion, Filosofia moral y demas ciencias que pueden facilitarle el conocimiento del hombre» ${ }^{56}$, dejando claro que, en primer lugar, deben conocer el «Derecho común y patrio» mientras Noriega insiste en el «discernimiento de lo justo é injusto, que es la ciencia legal» y en la necesidad de que en «las Universidades se empezase á poner el mayor cuidado en la instruccion de los que desean entrar en esta carrera, conforme á las Reales deliberaciones ${ }^{57}$.

Parece evidente que uno de los colectivos a los que estaba dirigido este tipo de lecciones era a los pretendientes de corregimientos y alcaldías mayores que deambulaban por la Corte en busca de destino. Los ciclos monográficos sobre instituciones de la Monarquía o el repaso sistemático a recopilaciones legislativas, habituales en estas academias, refuerza esta idea pero, además, la temática de algunas de estas conferencias y de otras no recogidas aquí (sobre política de fomento o el nuevo viraje que está sufriendo la ciencia de la policía) nos llevan a concluir que también podían servir para preparar las disertaciones que los candidados a la «carrera de varas» debían reañizar. Como demuestra la única analizada, la del

56. Memorial literario..., 4.1784, pp. 56-59.

57. Memorial literario..., 9.1784, pp. 14-17.

(C) Ediciones Universidad de Salamanca / ®@ Stud. his., H. ${ }^{a}$ mod., 39, n. 1 (2017), pp. 229-262 
MANUEL AMADOR GONZÁLEZ FUERTES

¿EL HÁBITO HACE AL MONJE? INSTITUCIONALIZACIÓN DE LA CARRERA JUDICIAL

EN ESPAÑA A FINALES DEL ANTIGUO RÉGIMEN

abogado catalán José Nuix y Catalán ${ }^{58}$, este tipo de textos coincide temática y formalmente con las lecciones impartidas en las academias y todo parece indicar que estas resultaban atractivas para los pretendientes como lugares donde inspirarse, aprender o, incluso, copiar, como hemos visto que insisten los fiscales del Consejo en sus informes y llega a apuntar Guardiola en su libro.

Volvemos a presenciar así otro ámbito, en este caso para los pretendientes a varas, en donde unificar criterios, establecer normas no escritas y, en fin, homogeneizar conductas con el fin de presentar disertaciones que no fueran acusadas de extravagantes e impidiesen cumplir el trámite necesario para acceder a la carrera judicial.

\section{EPÍlOgo. ¿EL ARTE de LA SIMULACIÓN? LA DIfÍCIL DETERMINACIÓN PRÁCTICA DE LA «SEGUNDA NATURALEZA» JUDICIAL}

Aunque Robert Darnton apunta en su estudio sobre los libelos franceses del siglo xviII respecto a la recepción de los textos que «el escepticismo hipercrítico ante la evidencia puede ser paralizante ${ }^{59}$ sí conviene resaltar, como él hace en ese pasaje, la dificultad para determinar las consecuencias reales de los planteamientos teóricos. Hasta aquí hemos visto cómo se iba configurando, de una manera no lineal y sin abandonar la concepción tradicional, una conciencia nueva sobre lo que debía ser un corregidor o un alcalde mayor. Poco a poco iba calando entre los publicistas y los legisladores la necesidad de aumentar el peso de las capacidades técnicas letradas en la designación y en el comportamiento de corregidores y alcaldes mayores. Hemos intentado demostrar que la institucionalización de una carrera letrada tras las normas de 1783 abre la puerta a este cambio de mentalidad sobre la naturaleza del juez aunque el respeto por la tradición y la pervivencia de otro tipo de servidores regios impedían, desde los planos legal y mental, la generalización de estos planteamientos. Pero más difícil resulta determinar en la práctica si tales planteamientos se cumplían en realidad. Tal trabajo, que supera con creces los límites de este texto, resulta un desafío para futuras investigaciones. Aún así, sí conviene reflexionar sobre tal posibilidad. Para ello, utilizaremos una

58. Bono Guardiola, M. J.: «El proyecto de reforma de la Administración Territorial: la Disertación sobre la importancia de la Justicia de D. José de Nuix y Perpiñá, pretendiente al cargo de Corregidor», en González Beltrán, J. M., Pereira Iglesias, J. L. y Bernando Ares, J. M. de (coords.): Actas de la V Reunión Científica Asociación Española de Historia Moderna, vol. 2, Cádiz, 1999, pp. 73-82.

59. Darnton, R.: El diablo en el agua bendita o el arte de la calumnia de Luis XIV a Napoleón. México, 2014 (1. edición en Filadelfia, 2009).

(C) Ediciones Universidad de Salamanca / ®@ Stud. his., H. ${ }^{a}$ mod., 39, n. 1 (2017), pp. 229-262 
MANUEL AMADOR GONZÁLEZ FUERTES

¿EL HÁBITO HACE AL MONJE? INSTITUCIONALIZACIÓN DE LA CARRERA JUDICIAL

EN ESPAÑA A FINALES DEL ANTIGUO RÉGIMEN

documentación puntual que necesitará ser corroborada por investigaciones más amplias.

Entre las fuentes a utilizar se encuentran las relaciones de méritos que presentaban a las instituciones oficiales en donde se resumían sus méritos para entrar en la carrera judicial o ascender en la misma. Los servidores reales que deseaban promocionar solían incluir, aunque esta documentación no ha sido utilizada por los historiadores centrados en la reconstrucción de sus carreras, un breve resumen de las principales actuaciones en sus cargos anteriores. Estos resúmenes, que se vinculan con los informes que debían presentar tras acabar su mandato, estaban limitados, como también lo estaban los informes, por su autor, el propio corregidor o alcalde mayor que resaltaría sus logros y eliminaría todo aquello que pudiera resultar negativo para sus intereses. Nos encontramos así con una fuente que revelaría, más allá de su labor, lo que el juez creyese que se deseaba escuchar, es decir, un «modelo ideal». Estas tergiversaciones que limitan el valor de la fuente son, por el contrario, para nosotros muy útiles por la presentación de estos «modelos ideales» de comportamiento.

Como botón de muestra hemos elegido un único caso, la labor desempeñada por Juan Sebastián Neri y Villarroel en el corregimiento de de Onteniente entre 1784 y $1792^{60}$. La lectura de lo presentado a la secretaría de la Cámara de Castilla nos remite a una acción de gobierno que centraba su interés en la mejora material de la jurisdicción -sin incrementar la presión fiscal- (plantación de numerosos árboles, mejora de las vías públicas y de edificios como la cárcel y la carnicería), exaltación del poder regio (tanto en las rogativas por la salud de Carlos III como en las fiestas de la proclamación de Carlos IV), cumplimiento de las órdenes reales (en relación con los gitanos o con la creación de cementerios extramuros), desempeño de las comisiones encomendadas por el Consejo Real y la Audiencia de Valencia, lo que también suponía un alto grado de confianza en sus capacidades, fomento de las actividades productivas (las relacionadas con el sector primario -desecación de un pantano e incremento del regadío- y el secundario -construcción de «quinientos tornos de hilaza de todas clases»-) y desempeño de su labor judicial como el apresamiento el 18 de mayo de 1790 del «famoso malhechor Francisco García, vulgo Quatro Ojos» o la constancia de

que no ha sido procesado, apercibido, ni multado, ó reconvenido por alguno de los Tribunales supreiores; y que ántes bien les ha merecido la mayor confianza por haber cumplido en sus Corregimientos y Alcaldía Mayores con quanto previenen las Reales Instrucciones.

60. AHN, Cons., leg. 13.361, exp. 86.

(C) Ediciones Universidad de Salamanca / ®@ Stud. his., H. ${ }^{a}$ mod., 39, n. 1 (2017), pp. 229-262 
Todo ello acompañado, lo que resulta sumamente interesante, con una moderada actividad independiente. Así, respecto a los gitanos «con fecha de veinte y tres de Enero de mil setecientos ochenta y cinco expuso lo que convendría prohibirles para reducirlos á sociedad, y conseguir la fuesen útiles» o, sobre el fomento de obras públicas «expuso á S. M. convendria para la mejor servidumbre de aquella Villa se levantasen ciertos puentes, y allanasen las cuestas del Camino Real de Valencia, Cataluña y Aragón».

Toda esta actividad ayuda a comprender las causas por las que la mayor importancia que se estaba pretendiendo introducir a la formación letrada no podían aún sustituir a las antiguas ideas de comportamiento defendidas por la tratadística. Como representante directo del monarca, el corregidor o alcalde mayor se encargaba de gran cantidad de actividades no judiciales que debían de ser reguladas, desde un punto de vista ideológico, por un comportamiento honrado, activo, celoso, íntegro y moralmente irreprensible. A estas características que no convenía eliminar había que ir introduciendo la capacitación judicial, pues ya sabemos que la separación de competencias no entraba en el esquema mental de los hombres del Antiguo Régimen.

Pero en la relación de méritos Juan Sebastián Neri también se añadía el respaldo que su labor tenía por parte de las autoridades locales. Nos relata cómo «los treinta y seis vocales de las tres Parroquias» de Onteniente en 1787 afirmaron que «sería perpetuamente feliz dicha Villa si lobraba ser gobernada siempre por el Juez que á la sazon tenía» y en 1790, cuando acaba su sexenio, los ayuntamientos de Villena -localidad de la que había sido corregidor-y Onteniente solicitaban al monarca el nombramiento de Neri para sus localidades y «el Común» de Alcira le solicitaba como su nuevo corregidor.

Con estas recomendaciones de diferentes agentes del cuerpo social entramos en otra fuente para conocer lo que esperaban los pueblos de sus corregidores. Pero esta fuente presenta problemas de interpretación mayores que la de las relaciones de méritos. En primer lugar, no se encuentra en un fondo documental y hay que recolectarla entre expedientes de jueces, nombramientos y procesos. Además, la intervención del cuerpo social solía limitarse a casos excepcionales: o positivos, como en el caso de Neri para quien solicitaban cargos y prórrogas, o negativos, donde se pedía el cese del delegado regio. También conviene tener en cuenta que las peticiones de los diferentes agentes sociales están siempre relacionadas con sus intereses particulares y su veracidad suele ser mucho más difícil de comprobar. Nos movemos en un terreno resbaladizo como demuestra, y lo hemos elegido expresamente, el último caso del que trataremos.

El 18 de julio de 1817 los regidores y el alguacil mayor de la localidad de Casas de Ves representaban a la superiridad que:

(C) Ediciones Universidad de Salamanca / ®@ Stud. his., H. ${ }^{a}$ mod., 39, n. 1 (2017), pp. 229-262 
MANUEL AMADOR GONZÁLEZ FUERTES

¿EL HÁBITO HACE AL MONJE? INSTITUCIONALIZACIÓN DE LA CARRERA JUDICIAL EN ESPAÑA A FINALES DEL ANTIGUO RÉGIMEN

El Ayuntamiento, señor, satisfecho de las recomendables prendas que asisten a aquel Magistrado [Juan Pérez de Cebrián] de literatura, instrucción en los negocios públicos, sumo celo en los del real servicio, moralidad en sus costumbres e integridad en la recta administración de justicia, no puede menos en cumplimiento de su deber y para llenar los deseos de estos vecinos de recurrir a v. M, elebándole sus sentimientos y los heroicos servicios que tiene contraídos el mencionado Alcalde mayor, según aparece de su relación de méritos adjunta. Ynfatigable al trabaxo ha conseguido en las pasadas turbulencia salbar a esta villa de los desastres y anarquía en que otras se han encontrado, ha puesto su policía en un estado floreciente, construyendo obras de fuentes y labaderos de que se carecía para la precisa e indispensable subsistencia, ha conservado los montes capaces en el día de socorrer todas sus atenciones y a beneplácito de la conservaduría general de lo interior del reino y, finalmente, ha puesto corrientes los títulos de esta villa, que hacía siglos no se abían presentado para su balimiento y confirmación, mereciendo las distinciones más particulares así del Yntendente de la probincia como de barios generales y gefes, que han mirado su gobierno como un modelo para los demás pueblos y estímulo de los de su carrera ${ }^{61}$.

Por todo ello solicitaban la concesión de una prórroga en la Alcaldía Mayor de la localidad para Juan Pérez de Cebrián. Pero dos meses y medio después el Síndico Personero del Común, el Diputado del Común, el Regidor segundo y dos vecinos representaban en muy diferentes términos:

Suplican que para evitar los males y perjuicios que esperimenta este vecindario no es combeniente dicha prórroga, pues está abandonada la justicia, las costumbres corrompidas, la religión abandonada, los escándalos públicos no evitados ni corregidor y siendo tres leguas de esta villa su naturaleza, sus parientes extraen maderas y leña acabando con el término y carrascas, los montes destruidos con roturas y quemado, de modo que hay más abierto que lleco y aunque les lleba las denuncias y multas se los deja en posesión y hacer propio lo ques de la villa, sin dar a los propios su tercera parte, no se escribe una letra de lo que podrá de poner el Mayordomo de propios, pues se parte entre el juez, esscribano y ministros. Es parcial y muy venal pues en mediando sus parientes todo es bueno ${ }^{62}$.

Y, por tanto, solicitaban que no se tramitara la solicitada prórroga. Lo particular de estas desavenencias, que no eran extrañas ante peticiones de prórrogas o acusaciones de mal desempeño de sus funciones, era que en ambas representaciones dos individuos coincidían. Lo blanco se había convertido en negro en dos meses. Finalmente la Cámara decidió no prorrogar a Juan Pérez de Cebrián y consultar a un nuevo alcalde. Sirva este ejemplo para constatar las dificultades

61. AHN, Cons., leg. 13.257.

62. Ibidem.

(C) Ediciones Universidad de Salamanca / ®@ Stud. his., H. ${ }^{a}$ mod., 39, n. 1 (2017), pp. 229-262 
MANUEL AMADOR GONZÁLEZ FUERTES

¿EL HÁBITO HACE AL MONJE? INSTITUCIONALIZACIÓN DE LA CARRERA JUDICIAL

EN ESPAÑA A FINALES DEL ANTIGUO RÉGIMEN

de interpretación de la documentación que quizá pudiéramos comprender con la consulta de fuentes locales.

Y, sirva también para resaltar las posibilidades y limitaciones de futuras investigaciones y constatar que a pesar de que, poco a poco y con incongruencias, se estaba intentando crear un nueva figura de juez con un incremento significativo de la capacitación técnica letrada, en numerosas ocasiones los delegados regios se seguían comportantdo al margen de su supuesta «segunda naturaleza», ejerciendo un poder absoluto y arbitrario en el ámbito local de su competencia desprestigiando la delegación de poder concedida por el monarca. Aunque, como decía Pascal, pudiera ser que esta «naturaleza» primitiva de poder despótico no fuera «primero un hábito»...

\section{Bibliografía}

Albi, F.: El corregidor en el municipio español bajo la Monarquía absoluta (ensayo histórico-crítico). Madrid, Instituto de Estudios de Administración Local, 1943.

Bono Guardiola, M. J.: «El proyecto de reforma de la Administración Territorial: la Disertación sobre la importancia de la Justicia de D. José de Nuix y Perpiñá, pretendiente al cargo de Corregidor», en González Beltrán, J. M., Pereira Iglesias, J. L. y Bernando Ares, J. M. de (coords.): Actas de la V Reunión Científica Asociación Española de Historia Moderna. vol. 2, Cádiz, Universidad de Cádiz, 1999, pp. 73-82.

Bourdieu, P.: Meditaciones pascalianas. Barcelona, Anagrama, 1999 (1. a edición: París, Seuil, 1997).

Castillo de Bobadilla, J.: Política para corregidores y señores de vassallos, en tiempo de paz y de guerra, y para Inezes Ecclesiasticos y Seglares, y de Sacas, Aduanas, y de Residencias, y los Oficiales y para Regidores, y Abogados: y del valor de los Corregimientos, y Gouiernos Realengos y de las Órdenes. Madrid, Luis Sánchez, 1597, 2 vols.

Castillo de Bobadilla, J.: Política para corregidores y señores de vasallos, en tiempo de paz, y de guerra, y para prelados en lo espiritual, y temporal entre legos, Jueces de Comisión, Regidores, Abogados, y otros Oficiales Públicos: y de las Jurisdicciones, Preeminencias, Residencias, y salarios de ellos: y de lo tocante á las Ordenes y Caballeros de ellas. 2 vols., Madrid, Imprenta Real, 1775.

DARnton, R.: El diablo en el agua bendita o el arte de la calumnia de Luis XIV a Napoleón. México, Fondo de Cultura Económica, 2014 (1. a edición: Filadelfia, University of Pennsylvania Press, 2009).

Gay Escoda, J. M.: «La culminación de las reformas de la administración municipal durante la Ilustración: el establecimiento de la carrera de corregimientos y varas y la "Instrucción de corregidores”", Documentación jurídica, 60, 1988, pp. 1637-1759.

Gazeta de Madrid. 33, 25.4.1783.

GonzÁlez Alonso, B.: El corregidor castellano (1348-1808). Madrid, Instituto de Estudios Administrativos, 1970.

(C) Ediciones Universidad de Salamanca / ®@ Stud. his., H. ${ }^{a}$ mod., 39, n. 1 (2017), pp. 229-262 
MANUEL AMADOR GONZÁLEZ FUERTES

¿EL HÁBITO HACE AL MONJE? INSTITUCIONALIZACIÓN DE LA CARRERA JUDICIAL EN ESPAÑA A FINALES DEL ANTIGUO RÉGIMEN

Guardiola y SÁEz, L.: El corregidor perfecto, y juez exactamente dotado de las calidades necesarias y convenientes para el buen Gobierno Económico y Politico de los Pueblos, y la mas recta administración de Justicia en ellas; y avisado, entre otras cosas, de las muchas cargas y obligaciones de su Oficio: conforme todo á las Leyes Divinas, Derecho Real de España, y Reales Resoluciones hasta ahora publicadas sobre la nueva Planta y Escala admirable de los Corregimientos y Alcaldias Mayores de estos Reynos. Madrid, Imprenta y Liberaría de Alfonso López, 1785.

GuaRdiola y Sáez, L.: El corregidor perfecto, y juez dotado de las calidades necesarias $y$ convenientes para la recta administración de Justicia, y buen gobierno politico $y$ económico de los Pueblos; y avisado muy particularmente, entre otras cosas, de las muchas cargas y obligaciones de su oficio, con expresión de algunos medios ó reglas para defenderse jurídicamente en el juicio de residencia, sindicato ó capitulacion: conforme todo á las Leyes divinas, Derecho Real de España, y Reales resoluciones hasta abora publicadas sobre el nuevo método de proveerse y servirse los Corregimientos y Alcaldias Mayores del Reyno, asi de Realengo y Ordenes Militares, como de Señorio. Madrid, Imprenta Real, 1796.

Kantorowicz, E. H.: Los dos cuerpos del rey. Un estudio de teología política medieval. Madrid, Alianza, 1985 (1. a edición: Princeton, Princeton University Press, 1957).

Martín de Balmaseda, F.: Decretos del rey don Fernando VII. Año primero de su restitución al trono de las Españas. Se refieren todas las reales resoluciones generales que se han expedido por los diferentes ministerios y consejos desde 4 de mayo de 1815 hasta fin de diciembre de igual año. Madrid, Imprenta Real, 1816.

Memorial literario, instructivo y curioso de la Corte de Madrid. núms. I-XXIV, Madrid, Imprenta Real, 1784-1785.

Ortiz de Zúñiga, M. L. y Herrera, C. de: Apendice a la obra titulada deberes y atribuciones de los correjidores, justicias y ayuntamientos de España. Madrid, Imprenta de Tomás Jordan, 1833.

Ortiz de Zúñiga, M. L. y Herrera, C. de: Deberes y atribuciones de los correjidores, justicias y ayuntamientos de España. Madrid, Imprenta de Tomás Jordan, 1832, 4 vols.

ORTIZ De ZÚÑIgA, M.: Biblioteca judicial, ó tratado original y metódico de cuanto hay vigente en la legislación, y en la práctica con relación á los juzgados de primera instancia. Madrid, Tomás Jordán, 1839.

Ortiz de ZúÑiga, M.: Biblioteca judicial. Parte tercera, en que se contienen la organizacion y atribuciones de las audiencias y del Tribunal Supremo de Justicia. Madrid, Tomás Jordán, 1840.

Pascal, B: Pensamientos de Pascál sobre la religión traducidos al español por don Andrés Boggiero. Zaragoza, Viuda de Blas Miedes, 1790.

Pascal, B: Pensées de M. Pascal sur la religion, et sur quelques autres sujets, qui ont esté trouvées après sa mort parmy ses papiers. París, G. Desprez, 1669.

Peset Reig, M.: «Derecho romano y Derecho real en las universidades del siglo XvinI», Anuario de Historia del Derecho Españo, XLV, 1975, pp. 273-339.

(C) Ediciones Universidad de Salamanca / ®@ Stud. his., H. ${ }^{a}$ mod., 39, n. 1 (2017), pp. 229-262 
MANUEL AMADOR GONZÁLEZ FUERTES

¿EL HÁBITO HACE AL MONJE? INSTITUCIONALIZACIÓN DE LA CARRERA JUDICIAL

EN ESPAÑA A FINALES DEL ANTIGUO RÉGIMEN

Ramón Solans, F. J.: "La Virgen del Pilar dice...» Usos politicos y nacionales de un culto mariano en la España contemporánea. Zaragoza, Prensas de la Universidad de Zaragoza, 2014.

Real Cédula de S. M. y señores del Consejo, en que se aprueba la instrucción inserta de lo que deberán observar los corregidores y alcaldes mayores del reyno. Madrid, Imprenta de Don Pedro Marín, 1788.

Real Cédula de S. M. y señores del Consejo, por la qual se establecen reglas y providencias que deben observarse en lo succesivo para el modo de proveerse y servirse los Corregimientos y Alcaldias mayores de los Reynos de Castilla y Aragon, é Islas adyacentes. Madrid, Pedro Marín, 1783.

Risco, A.: La Real Academia de Santa Bárbara de Madrid (1730-1808). Toulouse, Université de Tolulouse-Le Mirail, 1979, 2 vols.

Roldán Verdejo, R.: Los jueces de la Monarquía Absoluta. Su estatuto y actividad judicial. Corona de Castilla, siglos XIV-XVIII. Santa Cruz de Tenerife, Universidad de La Laguna, 1989.

Sánchez, S.: Colección de todas las pragmáticas, cédulas, provisiones, circulares, autos acordados, vandos y otras providencias publicadas en el actual reynado del señor don Carlos IV. Tomo III. Madrid, Imprenta de la viuda e hijo de Marín, 1801.

Santayana Bustillo, L. de: Govierno politico de los pueblos de España, y el corregidor, alcalde, juez de ellos. Zaragoza, Imprenta de Francisco Moreno, 1742.

(C) Ediciones Universidad de Salamanca / ®@ Stud. his., H. ${ }^{a}$ mod., 39, n. 1 (2017), pp. 229-262 